Vol. 23 N.1 de 2020 ISSN: 1516-8182

Recebimento: 07/09/2019

Aceite: 19/11/2019

Doi: $0.25059 / 2527-2594 /$ retratosdeassentamentos/2020.v23i1.387

\title{
Plantar prá que? Os efeitos do esvaziamento do PAA no assentamento Córrego Rico - SP
}

\author{
Regina Aparecida Leite de Camargo ${ }^{1}$ \\ Matheus Ferreira Bocca ${ }^{2}$ \\ Otávio Luis Almeida ${ }^{3}$ \\ Luís Rodrigo Ribon Pinotti ${ }^{4}$ \\ Artur Pizardo Micheletto ${ }^{5}$
}

Resumo: O Programa de Aquisição de Alimentos (PAA) instituiu o primeiro aparato legal para a aquisição governamental de gêneros alimentícios da agricultura familiar por instrumento outro que as licitações públicas. A modalidade do PAA que mais beneficia os assentados da reforma agrária, e também a mais alinhada com a dupla finalidade do programa de fortalecimento da agricultura familiar e promoção da segurança alimentar, é a Compra com Doação Simultânea. Mas essa, como outras de suas linhas de atuação, vem sofrendo com a diminuição de recursos e aumento de exigências administrativas e burocráticas desde o ano de 2013. O presente artigo apresenta dados recentes sobre o PAA e os efeitos das mudanças do programa no assentamento Córrego Rico, comparando entrevistas realizadas com os participantes do programa no final de 2015 e em agosto de 2019. Apesar de não ter sido possível identificar um aumento da insegurança alimentar entre os entrevistados, medida pela Escala Brasileira de Insegurança Alimentar (EBIA), os resultados demonstraram que a dificuldade de acessar mercados institucionais por esse instrumento de política pública diminuiu a diversidade de cultivos, o que afeta a alimentação das famílias e sua capacidade de reprodução como agricultores familiares.

Palavras-Chave: Políticas públicas. Agricultura Familiar. Insegurança Alimentar. Diversificação Da Produção.

\section{Why to Plant? The efFects of PaA EMPTying in the CórRego Rico/SP SetTlement}

Abstract: The Food Acquisition Program (PAA) instituted the first legal tool for governmental acquisition of family farming products by an instrument other than the public procurement. The PAA modality that most benefits agrarian reform settlers and is best aligned with the program dual purpose of strengthening family farming and promoting food security is the Purchase with Simultaneous Donation. However, this, like others of the program lines of action, suffers from the decrease of resources and increase of administrative and bureaucratic requirements since 2013. This paper presents recent data on the PAA and the effects of the program changes on the Córrego Rico settlement area, comparing interviews with program participants

\footnotetext{
${ }^{1}$ Faculdade de Ciências Agrárias e Veterinária Departamento de Economia, Administração e Educação Políticas Públicas para a agricultura familiar, agroecologia, extensão rural, educação ambiental. Universidade Estadual Paulista "Júlio de Mesquita Filho". E-mail: regina.camargo@unesp.br

${ }^{2}$ Engenheiro Agrônomo Autônomo. E-mail: matheusfbocca@agronomo.eng.br

${ }^{3}$ Dicente de Engenharia Agronômica - Universidade Estadual Paulista "Júlio de Mesquita Filho". E-mail: otavioluisalmeida93@ gmail.com

${ }^{4}$ Dicente de Engenharia Agronômica - Universidade Estadual Paulista "Júlio de Mesquita Filho". E-mail: 1rrpinotti0@gmail. com

${ }^{5}$ Graduando em Técnico em Agropecuária Colégio Técnico Agrícola "José Bonifácio"/UNESP. E-mail: arturmicheletto@ gmail.com
} 
the end of 2015 and August 2019. Although it was not possible to identify an increase in food insecurity among families interviewed, measured by the Brazilian Food Insecurity Scale (EBIA), the results showed that the difficulty of accessing institutional markets through this public policy instrument decreased crop diversity, which the consequent effect on household diets and their ability to reproduce themselves as family farmers.

KeYwORDs: Family farming. Food insecurity. Public policies. Production diversification.

\section{INTRODUÇÃO}

Políticas de crédito, assistência técnica e extensão rural e mercados direcionadas especificamente para o público que compõe a agricultura familiar representam o reconhecimento de sua importância como agente econômico, categoria social e ator político. A recente diminuição de recursos para esses programas sinaliza não apenas a postura da atual administração federal, mal disfarçada sob a bandeira de "uma só agricultura", como o enfraquecimento dos movimentos sociais e instâncias representativas dos diferentes segmentos que podem ser agrupados no leque de possibilidades que o conceito de agricultura familiar abriga. À exceção do movimento indígena, que mais tem se destacado na luta por seus direitos e sofrido as consequências das políticas emedidas dogovernofederale administrações estaduais.

O Programa de Aquisição de Alimentos (PAA), criado pela Lei 10.696 e Decreto 4.772, ambos de 2003, instituiu o primeiro aparato legal para a aquisição governamental de gêneros alimentícios da agricultura familiar por instrumento outro que as licitações públicas regidas pela Lei 8.666. De caráter intersetorial e interministerial, o programa busca atender antigas demandas dos movimentos sociais e velhas dívidas com a agricultura familiar, entre elas sua menor participação na Política de Garantia de Preços Mínimos (PGPM). O PAA nasceu no bojo do Programa Fome Zero, para complementar a distribuição de renda expandida pelo Programa Bolsa Família no início do primeiro governo do Partido dos Trabalhadores (CAMARGO, et al, 2013). Além de garantir novas possibilidades de mercado para o produtor familiar, o programa tem, como um de seus objetivos principais, a promoção da segurança alimentar e nutricional para as famílias produtoras e aquelas em vulnerabilidade social, receptoras dos alimentos distribuídos pelo PAA na sua linha de atuação Compra com Doação Simultânea (GRISA et al, 2011; HESPANHOL, 2013).

Mas apesar do seu comprovado impacto econômico e social, nas áreas onde sua implementação foi mais efetiva, o PAA passa por um processo de esvaziamento 
que teve início em 2013 e acirrou-se a partir de 2016. Esse esvaziamento ocorre em três frentes distintas mas complementares: a redução drástica dos recursos destinados ao programa; sua criminalização através da operação "Agro-fantasma" e o aumento da burocracia e exigências para a aprovação e condução dos projetos.

Com a diminuição do acesso a mercados institucionais via PAA, resta indagar se os ganhos do programa em diversificação da produção e alimentação e maior segurança alimentar e nutricional para as famílias produtoras permanecem, ou se essas famílias voltaram à mesma situação de vulnerabilidade e restrição das possibilidades de escoamento da produção anteriores ao programa.

Esse trabalho retoma os resultados encontrados em vinte e uma entrevistas realizadas no assentamento Córrego Rico, parte de uma pesquisa nos anos de 2015 e 2016 com 144 famílias assentadas de quatorze áreas de assentamento, onde foram avaliadas a participação no PAA e no Programa Nacional de Alimentação Escolar (PNAE) e a segurança alimentar das famílias pela aplicação da EBIA. Das vinte e uma famílias originalmente entrevistadas no Córrego Rico, dezoito foram novamente visitadas em agosto de 2019. Dentre as três famílias que não foram entrevistadas, uma havia deixado o assentamento e duas pouco estavam produzindo no momento da pesquisa por motivo de doença na família e dedicação a outras atividades. A seguir são recuperadas algumas das principais características do PAA enquanto um programa inovador na arena das políticas públicas, as principais modificações no programa desde 2013 e as consequências para os assentados do Córrego Rico do seu progressivo esvaziamento.

\section{O Programa de Aquisição de Alimentos: um exemplo de inovação EM POLÍtiCAS PÚBLICAS}

Os programas de políticas públicas específicos para a agricultura familiar já foram bastante estudados por autores de diferentes áreas disciplinares (GRISA 2009, GRISA; PORTO, 2015; HESPANHOL, 2013; DELGADO, 2013; SABOURIN, 2014). O embrião desses programas é normalmente reportado ao ano de 1996, data da criação do Programa Nacional de Fortalecimento da Agricultura Familiar (PRONAF), mas Mattei (2015) chama atenção para a criação, em 1994, do seu antecessor, o Programa de Valorização da Pequena Produção Rural (PROVAP), cujo nome ainda não havia incorporado a terminologia "agricultor familiar", adotada a partir de 1996. Na mesma linha encontrava-se o Programa de Apoio ao Pequeno Produtor do Nordeste (PAPP), implantado nos estados da região nordeste no início da década de 1990, com recursos do Banco Mundial (SOARES, 1996).

Apesar das diferenças em abrangência, arranjos institucionais, formas de governança e alguns objetivos específicos ou mesmo gerais, esses programas 
têm em comum o reconhecimento da necessidade de medidas específicas para a agricultura familiar, que aumentem suas possibilidades de reprodução e fortaleçam sua capacidade produtiva e mercadológica.

São programas que trazem inovações em políticas públicas, definidas por Farah (2008) como capazes de responder a novos problemas emergentes ou dar respostas novas e eficazes para antigas questões, como o negligenciamento histórico da agricultura familiar no Brasil. Parte dessa inovação diz respeito à transferência de recursos e competências para os entes federativos, possibilitada pela Constituição de 1988, que garante maior participação social na formulação e implementação de políticas públicas. Para Farah (2006), a inovação em políticas públicas pode se dar por produto ou por processo. A inovação por produto relaciona-se com o próprio conteúdo de uma política, quem é beneficiado e quais são seus objetivos.

Nesse caso, a inovação implica na democratização do acesso a essa política, ou seja, na inclusão de novos setores da sociedade, como no caso da participação de produtores familiares em mercados institucionais facilitada pelo PAA e PNAE. Já a inovação por processo refere-se à como a política é implementada, quem são os atores e aparatos administrativos envolvidos. A inovação, nesse caso, recai sobre os processos decisórios e a forma de gestão e provisionamento dos serviços públicos, incluindo novos atores no planejamento e gestão da política. No caso do PAA, a inovação por processo aparece na formação de um Grupo Gestor atuando em diferentes níveis administrativos, com caráter intersetorial e, na esfera da administração federal, também interministerial. E ainda na participação de representantes das organizações de produtores em conselhos municipais e estaduais.

Peter Spink (2006), ao discorrer sobre o Programa Gestão Pública e Cidadania, elenca os elementos necessários para que uma iniciativa em gestão pública seja considerada uma inovação:

Ser um novo programa ou um conjunto de novas atividades de um programa existente, que represente mudança significativa, em qualidade ou quantidade, nas práticas anteriormente adotadas para a temática em foco.

Nesse caso, considerando-se o dublo objetivo principal do PAA - fortalecimento da agricultura familiar e promoção da segurança alimentar (DELGADO, 2013), trata-se de um programa novo, mas inserido em uma política mais ampla de combate à fome e que, em princípio, deveria também complementar a política de crédito diferenciado implantada em 1996 com o Pronaf. Ainda que programas anteriores, como o PAPP, investissem na diversificação da produção e maior 
inserção da agricultura familiar no mercado, o que traria benefícios para a renda e consequentemente para a alimentação das famílias contempladas; não estabeleciam uma relação afirmativa entre a capacidade produtiva da agricultura familiar, numericamente comprovada nos censos agropecuários de 1996, $2006 \mathrm{e}$ 2017, e o suprimento alimentar das próprias famílias produtoras e da população urbana em vulnerabilidade social.

\section{- Ser replicável em outras regiões}

A difusão de políticas públicas para a agricultura familiar para outros países, sejam da América Latina e Caribe (SABOURIN; CRISA, 2018) ou africanos, como no caso do PAA África (CASTRO, 2018) demonstra que, feitas as devidas adaptações regionais, o conceito norteador do programa apresenta replicabilidade suficiente para despertar o interesse da administração pública e instituições de outros países ou organismos internacionais. No Brasil, a disseminação do programa pelas regiões do país ocorreu de forma desigual ao longo dos anos e nas suas diferentes modalidades, como será visto nesse trabalho. No estado de São Paulo, sua importância sempre foi maior em municípios com áreas de assentamento (CAMARGO et al, 2013)

- Expandir o diálogo entre sociedade e agências públicas e também a qualidade da prática política e institucional

A participação no PAA demandou, da maioria das cooperativas e associações, uma aproximação com funcionários da Companhia Nacional de Abastecimento (Conab), órgão público até então distante da agricultura familiar. É a Conab que gerencia a PGPM e, através de seus instrumentos novos e antigos, divulga o preço mínimo de uma lista de produtos não perecíveis e mantém os estoques reguladores do país. O PAA também aproximou os produtores de prefeituras municipais e entidades locais, principalmente as das redes socioassistenciais. Essa aproximação, e principalmente o fornecimento de alimentos, permitiu o maior reconhecimento das organizações e agricultores familiares, principalmente em casos em que a inclusão social é mais difícil, como acontece com as áreas de assentamento.

- Promover o desenvolvimento responsável, com utilização de recursos locais e/ou nacionais e adoção de práticas endógenas e auto sustentáveis.

Embora a compra de produtos orgânicos pelo PAA não seja tão expressiva quanto o seu potencial de fortalecer a agroecologia e agricultura orgânica (GALINDO et al, 2014), o fato do programa propor pagar 30\% a mais por esse tipo de produto em relação ao convencional, deveria estimular os agricultores a adorarem sistemas de produção que sigam o princípio da coprodução com a natureza (PLOEG, 2008). A produção sustentável faz parte dos princípios do programa, embora o mesmo não especifique maneiras complementares de atingi-la. 
O caráter interministerial e intersetorial do PAA reforça sua característica de política pública inovadora, bem como a pluralidade do Grupo Gestor e dos gestores executores locais. Segundo Grisa (2009) e Almeida e Ferrante (2009), o potencial de formador de capital social do PAA manifesta-se sobretudo na modalidade Compra com Doação Simultânea, por movimentar uma ampla rede de atores sociais no âmbito local.

Para Porto et al (2014, p.39), o programa inova em quatro frentes complementares: determinou "recursos e metodologia específica para compras públicas de alimentos oriundos da agricultura familiar"; promoveu a "relação direta entre governo e sociedade civil para a aquisição de alimentos por parte do Estado; definiu preços "coerentes e adequados às especificidades regionais e locais" e instituiu "uma gestão compartilhada entre seis ministérios, assegurando interinstitucionalidade".

Apesar das recentes mudanças ministeriais, o PAA continua funcionando em seis modalidades, com recursos do Ministério da Cidadania, antigo MDS, e do Ministério da Agricultura, Pecuária e Abastecimento (MAPA), através da Conab. No Quadro 1 encontram-se os limites de recursos que um produtor individual ou uma organização da agricultura familiar pode acessar em cada modalidade atualmente.

A linha Apoio à Formação de Estoques trata-se na verdade de uma operação de financiamento da comercialização, semelhante ao instrumento EGF (Empréstimo do Governo Federal) da PGPM.

A modalidade Compra com Doação Simultânea pode, atualmente, ser executada através de um Termo de Adesão firmado entre o Ministério da Cidadania e a administração de estados e municípios; situação em que o produtor fornecedor dos estados e municípios que aderiram ao programa recebem pelos produtos entregues diretamente do Ministério da Cidadania, através de cartão bancário próprio. Ou via um termo de cooperação do Ministério da Cidadania com a Conab, em cujo caso só podem participar associações e cooperativas com DAP Jurídica, e o pagamento é realizado pela Conab, com recursos repassados pelo Ministério. O PAA Doação Simultânea permite o pagamento de até 30\% a mais para produtos orgânicos, como acima mencionado. Os produtos são entregues diretamente para as entidades beneficiadas da rede socioassistencial.

Na modalidade Compra Direta, os produtos são adquiridos pela Conab com recursos do Ministério da Cidadania e depois repassados para entidades da rede socioassistencial ou filantrópicas de ensino. Essa modalidade corresponde ao instrumento Aquisição do Governo Federal (AGF) da PGPM.

Pela modalidade Aquisição de Sementes, a Conab adquire as sementes de organizações com DAP Jurídica e as repassa para órgão parceiros como o INCRA, FUNAI, Instituto Chico Mendes, Fundação Cultural Palmares, secretarias estaduais 
da agricultura e entidades de assistência técnica e extensão rural.

Através do PAA Compras Institucionais, os estados, municípios e órgãos federais da administração pública direta e indireta podem efetuar a compra de produtos da agricultura familiar através do instrumento Chamada Pública, dispensando-se o procedimento licitatório regulado pela Lei 8.666/93. É a modalidade que permite maior volume de venda da agricultura familiar pelo PAA, já que o limite por produtor portador de DAP é de R $20.000,00$ /ano por órgão comprador, podendo o mesmo participar de mais de uma Chamada Pública nessa modalidade e também de outras linhas do PAA no ano. Essa é a linha que tem movimentado mais recursos atualmente, como será visto em seguida.

O uso do instrumento Chamada Pública para as compras públicas, com dispensa do procedimento licitatório, é uma inovação importante do programa, adotada também em 2009 para as compras de gêneros alimentícios da agricultura familiar pelo PNAE. Essa dispensa se justifica pelo objetivo desses programas, de promover a agricultura familiar e a soberania alimentar, em detrimento da compra pelo menor preço promovida na licitação pública. Está, portanto, alinhada com o objetivo expresso do PAA de "incentivar a agricultura familiar, promovendo a sua inclusão econômica e social, com fomento à produção com sustentabilidade, ao processamento, à industrialização de alimentos e à geração de renda" (BRASIL, 2019). 
Quadro 1 - Diferença entre limites das diferentes modalidades do PAA em vigor em 2019.

\begin{tabular}{|c|c|c|c|}
\hline Modalidade & Órgão executor & $\begin{array}{l}\text { Limite por DAP } \\
\text { Pessoa Física }\end{array}$ & $\begin{array}{l}\text { Limite por DAP } \\
\text { Pessoa Jurídica }\end{array}$ \\
\hline $\begin{array}{l}\text { Compra com Doação } \\
\text { Simultânea (CDS) }\end{array}$ & $\begin{array}{l}\text { - Ministério da Ci- } \\
\text { dadania/Estados e } \\
\text { municípios } \\
\text { - Ministério da Ci- } \\
\text { dadania/Conab }\end{array}$ & $\begin{array}{l}\text { RS } 6.000,00 \\
\text { R\$ } 8.000,00\end{array}$ & $\mathrm{R} \$ 2,0$ milhões \\
\hline $\begin{array}{l}\text { Apoio à Formação de } \\
\text { Estoques (CPR Es- } \\
\text { toques) }\end{array}$ & - Conab & $\mathrm{R} \$ 8.000,00 /$ ano & $\mathrm{R} \$ 1,5$ milhões/ano \\
\hline $\begin{array}{l}\text { Compra direta da } \\
\text { agricultura familiar } \\
(\mathrm{CDAF})\end{array}$ & - Conab & $\mathrm{R} \$ 8.000,00 / \mathrm{ano}$ & $\mathrm{R} \$ 500.000,00$ \\
\hline $\begin{array}{l}\text { Incentivo à produção } \\
\text { e consumo de leite }\end{array}$ & $\begin{array}{l}\text { - Ministério da Ci- } \\
\text { dadania/estados da } \\
\text { SUDENE }\end{array}$ & R\$ 9.000,00/ano & \\
\hline Aquisição de sementes & - Conab & & $\mathrm{R} \$ 6,0$ milhões/ano \\
\hline Compra institucional & $\begin{array}{l}\text { - Estados, mu- } \\
\text { nicípios e órgãos } \\
\text { federais da adminis- } \\
\text { tração pública direta } \\
\text { e indireta }\end{array}$ & $\begin{array}{l}\mathrm{R} \$ 20.000,00 / \mathrm{ano} / \\
\text { órgão comprador }\end{array}$ & $\begin{array}{l}\mathrm{R} \$ 6,0 \text { milhões/ano/ } \\
\text { órgão comprador }\end{array}$ \\
\hline
\end{tabular}

Fonte: Organizado pelos autores com dados do Ministério da Cidadania. Brasil, 2019.

\section{O Esvaziamento do PAA}

Como argumentado na introdução desse trabalho, o PAA passa por um esvaziamento que pode ser identificado em três frentes: diminuição dos recursos; reflexos do processo de criminalização pela Operação Agro-fantasma, conduzida pela Polícia Federal em 2013 e maior burocratização do programa, associada a uma disputa mais acirrada pelos recursos por parte das organizações da agricultura familiar.

Para Valadares e Souza (2015), o lançamento do Programa Brasil sem Miséria em 2010 reforçou o papel do PAA como promotor da inclusão produtiva dos produtores familiares menos capitalizados ou em situação de extrema miséria. Porém, no final de 2012 e início de 2013, mudanças institucionais e normativas diminuíram o protagonismo da Conab no programa e passaram a privilegiar os 
termos de adesão firmados entre o então Ministério do Desenvolvimento Social e Combate à Fome (MDS) com estados e municípios. Essas mudanças explicam o aumento de recursos disponibilizados em 2012 e sua queda brusca em 2013.

Mas segundo Sales (2017), a diminuição dos recursos em 2013 foi também consequência do processo de criminalização sofrido pelo PAA a partir de 2011, quando a Polícia Federal iniciou investigações de desvios de verbas públicas na operacionalização do programa. As investigações atingiram quatorze municípios do estado do Paraná e resultaram em oito ações penais, com expedição de mandados de prisão de agricultores e funcionários da Conab. Ainda que posteriormente todos os acusados da Operação Agro-fantasma tenham sido absolvidos, uma vez que ficou comprovado que as irregularidades administrativas encontradas não se caracterizavam em ato de delito contra os cofres públicos, os agricultores continuaram a ser vistos como suspeitos e algumas associações e cooperativas tiveram o quadro de associados drasticamente reduzido. Dentro da Conab, a operação acarretou maior rigor e inflexibilização nos projetos e produtos entregues. Para Valadares e Souza (2015, p. 7) "A necessidade de aperfeiçoar e padronizar os controles administrativos determinou à Conab aplicar um freio de arrumação em suas ações no PAA". O próprio site da Conab afirma que "Nos últimos anos, a sistemática de distribuição dos recursos orçamentários/financeiros destinados à execução da modalidade CDS foi reavaliada, principalmente devido à exigência de maior controle e eficiência nos critérios do programa" (CONAB, 2019).

É possível argumentar que o endurecimento das normas da Conab fere alguns princípios de troca, de reciprocidade e de relações de vizinhança e parentesco inerentes às sociedades camponesas. Nesse sentido, Triches e Grisa (2015, p. 10) alegam que "[...] nem sempre se corrompem regras por má fé do gestor público ou do agricultor familiar, mas pela necessidade de fazer valer a finalidade da Política e de ajustá-la aos contextos locais”. No caso da Operação Agro-fantasma, o que foi apontado como irregularidade era, na maioria dos casos, "estratégias organizativas, considerando as peculiaridades da agricultura e sua total dependência da natureza (TRICHES; GRISA, 2015, p. 20). A intransigência da administração pública, nesse caso, transforma-se numa retórica perversa de desqualificação de uma política pública que vai contra os padrões instituídos da ordem econômica e social, ao inovar e incorporar novos atores no cenário das compras públicas.

A redução dos recursos em 2013 atingiu todas as modalidades do programa, mas mais severamente as operacionalizadas pela Conab. No caso da linha Compra com Doação Simultânea, a mediação da Conab e do Incra junto ao público dos assentamentos da reforma agrária estimulava a formação e participação de associações e cooperativas de agricultores familiares no PAA, importante para a 
inclusão dos produtores com menor capacidade produtiva (VALADARES e SOUZA, 2015).

Em 2014, os recursos do programa apresentaram uma recuperação parcial, sobretudo pelos montantes disponibilizados pelo MDS através dos Termos de Adesão firmados com estados e municípios, mas nunca voltaram aos patamares atingidos em 2012.

A Figura 1 ilustra a evolução dos recursos do PAA nos seus quinze anos de existência. Como pode ser observado, em 2012 o total de recursos chegou perto de 600 milhões de reais, caindo para pouco mais de R $\$ 200$ milhões em 2013 e não passando de R $\$ 63.3$ milhões em 2018. Desse total, 51,7 milhões (82\%) foram repassados para a modalidade Compra com Doação Simultânea. Em relação a distribuição de recursos pelas regiões do país, o Nordeste foi a região que mais recebeu recursos desde 2015, ficando com 44\% do total distribuído em 2018 (CONAB, 2019).

A região Centro-Oeste foi a menos contemplada com recursos do PAA desde o início do programa, ficando com apenas $8 \%$ dos valores em 2018. A participação da região Sul foi bastante significativa até 2013, acompanhando tendência já identificada na distribuição dos recursos do Pronaf (AQUINO; SCHNEIDER, 2015), mas em 2018 recebeu apenas $11 \%$ dos recursos do PAA. No mesmo ano, a região Norte ficou com $21 \%$ e o Sudeste com $16 \%$ dos montantes repassados pela Conab (CONAB, 2019).

Em relação a distribuição de recursos por modalidades, as figuras a seguir apresentam a variação de valores das modalidades Doação Simultânea e Formação de Estoques. A linha CDAF não recebeu recursos em 2018 e 2016, sendo também a que menos foi contemplada desde 2010.

Como pode ser comprovado nas figuras 2 e 3, as duas modalidades do PAA seguiram a tendência de aumento dos recursos em 2012 e drástica redução em 2013, com alguma recuperação em 2014 e gradativa diminuição desde então. 
Figura 1 - Variação dos recursos do PAA entre 2003 e 2018 nas diferentes regiões do país.

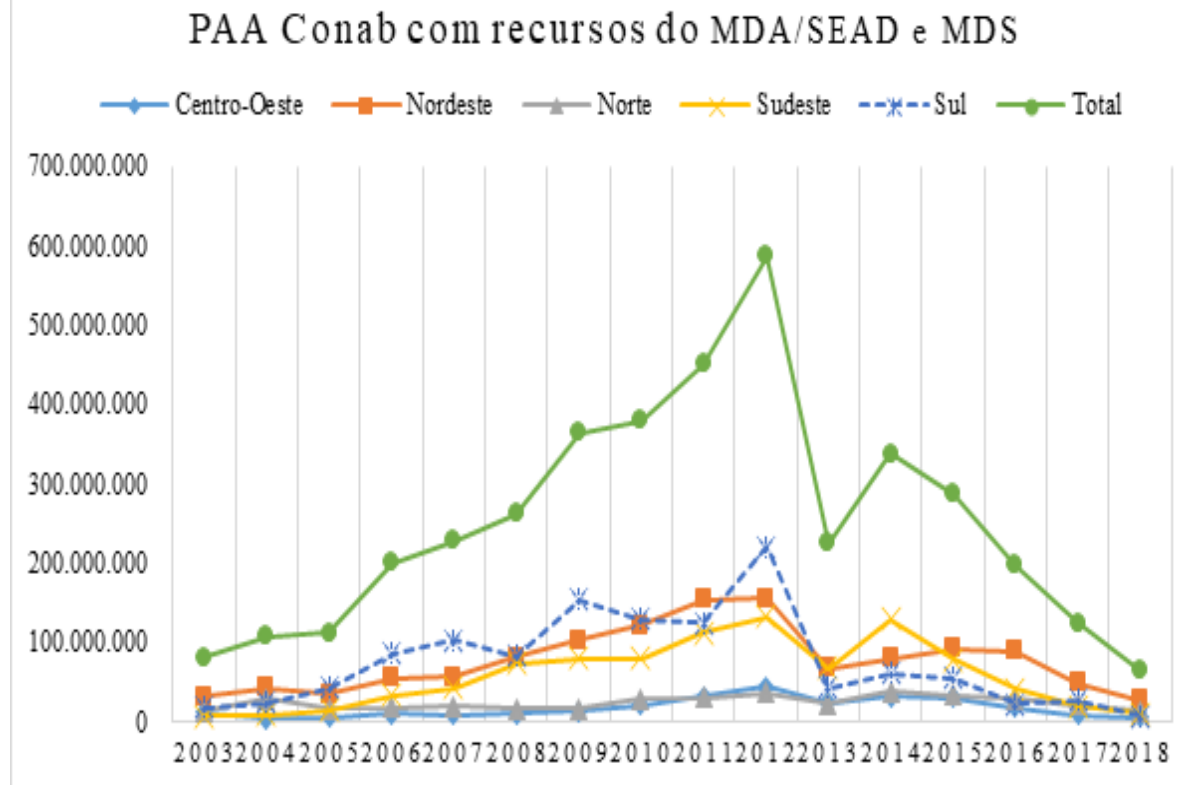

Fonte: Elaborado pelos autores com dados da Conab, 2019.

A compilação dos dados das mesmas modalidades para o estado de São Paulo resultou nas figuras 4 e 5, apresentadas a seguir:

Figuras 2 e 3 - Recursos operacionalizados pela Conab no PAA Doação Simultânea e Formação de Estoques entre 2010 e 2018.

\section{Recursos PAA Doação Simultânea}

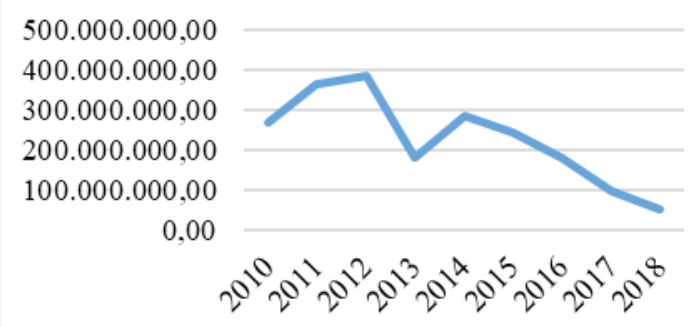

\section{Recursos PAA Formação de Estoques}

$50.000 .000,00$ $40.000 .000,00$ $30.000 .000,00$ $20.000 .000,00$ $10.000 .000,00$ 0,00

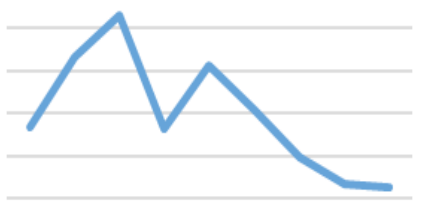

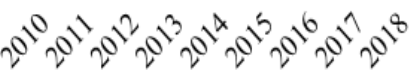

Fonte: Elaborado pelos autores com dados da Conab, 2019 
Figuras 4 e 5 - Recursos operacionalizados pela Conab no PAA Doação Simultânea e Formação de Estoques entre 2010 e 2018 no estado de São Paulo.

Recursos PAA Doação Simultânea em São Paulo

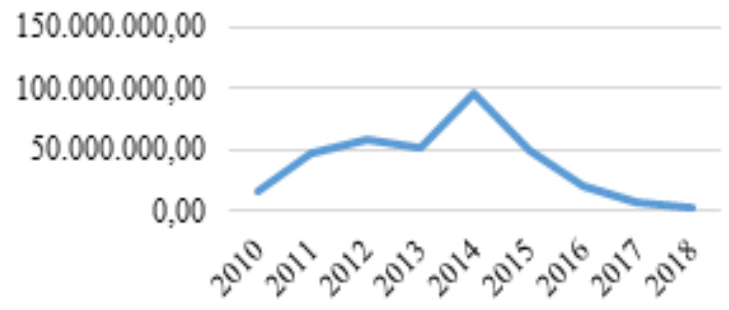

\section{Recursos PAA Formação de Estoques em São Paulo}

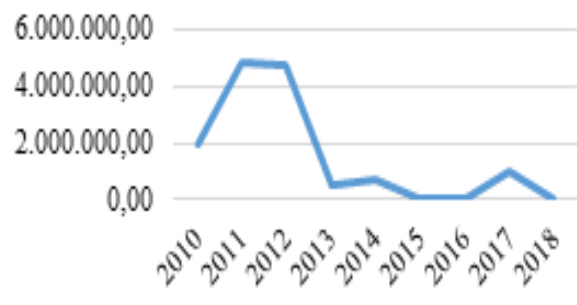

Fonte: Elaborado pelos autores com dados da Conab, 2019.

No caso do estado de São Paulo, verifica-se que o maior montante de recursos da modalidade Doação Simultânea foi operacionalizado em 2014, quando foram executados 297 projetos, o maior número dentre todos os estados brasileiros, somando R\$ 95,5 milhões. A partir de então, o programa sofre uma vertiginosa queda, com pouco mais de $\mathrm{R} \$ 3,0$ milhões executados em 2018. Já a modalidade Formação de Estoques praticamente não se recuperou da queda sofrida em 2013, ficando sem receber recursos nos anos 2015, 2016 e 2018.

Nos últimos anos a modalidade Compra Institucional do PAA é a que tem movimentado maior volume de recursos, pois trata-se de emprego de valores já destinados à aquisição de gêneros alimentícios por órgãos públicos, executados via Chamada Pública. Um levantamento dos produtos e estados contemplados por essas Chamadas nos anos 2017, 2018 e 2019 produziu as figuras abaixo:

Embora os dados das figuras de 6 a 11 refiram-se as Chamadas Públicas do PAA Compra Institucional que aparecem no site da Conab, e não ao balanço das compras efetivamente realizadas, é possível perceber que os estados mais beneficiados por essa modalidade do programa foram Bahia e Pernambuco, seguidos de Minas Gerais, Rio Grande do Sul, Paraná e Maranhão. No caso do estado de São Paulo, o maior volume de pedidos ocorreu no ano de 2018, no valor de R\$ 258.214,50. Uma possível explicação para a baixa adesão do estado a essa modalidade do PAA pode ser a concorrência com o Programa Paulista de Agricultura de Interesse Social (PPAIS), que também opera com compras da agricultura familiar por Chamadas Públicas. 
Figuras 6 e 7 - Chamadas na modalidade Compra Institucional do PAA no ano 2017 e 2018 . UF e valores.

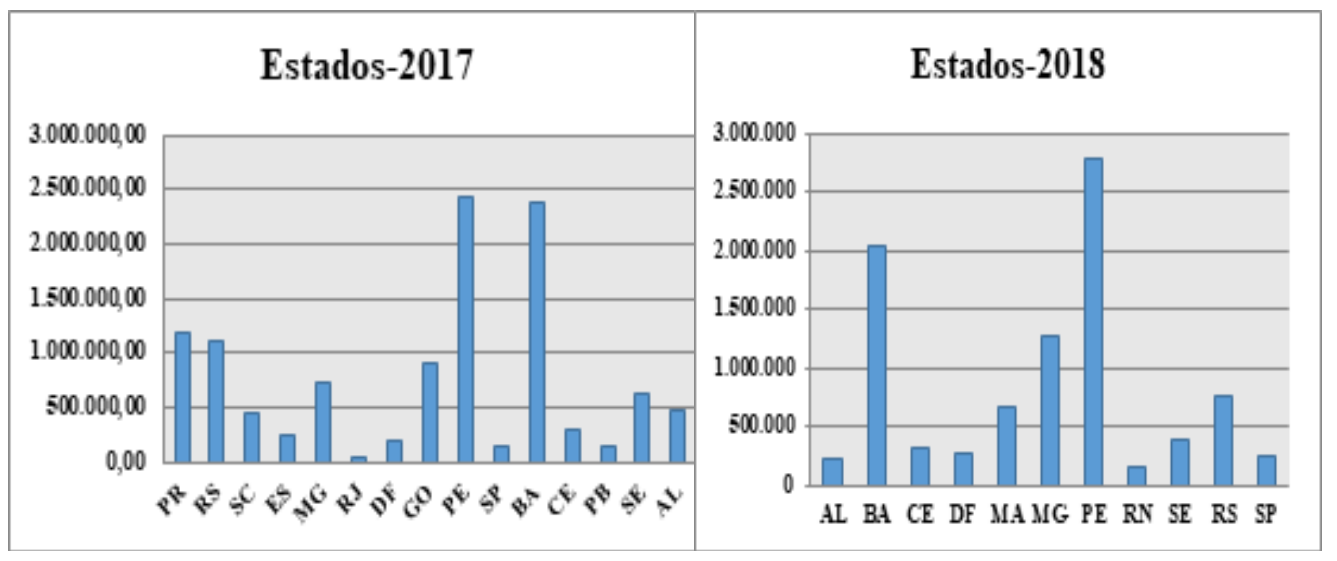

Fonte: Elaborado pelos autores. Conab. Brasil, 2019.

Figura 8 - Chamadas na modalidade Compra Institucional do PAA no ano 2019. UF e valores.

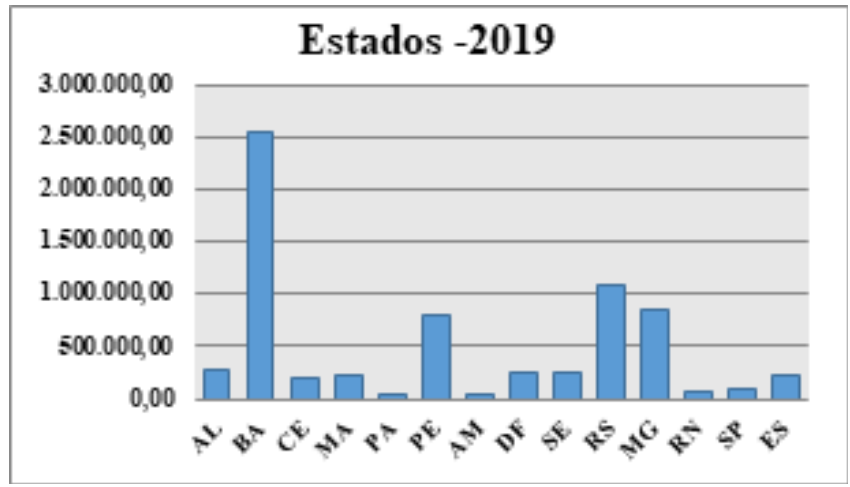

Fonte: Elaborado pelos autores. Conab. Brasil, 2019 
Figura 9 - Chamadas Compra Institucional do PAA no ano 2019. Produtos e valores.

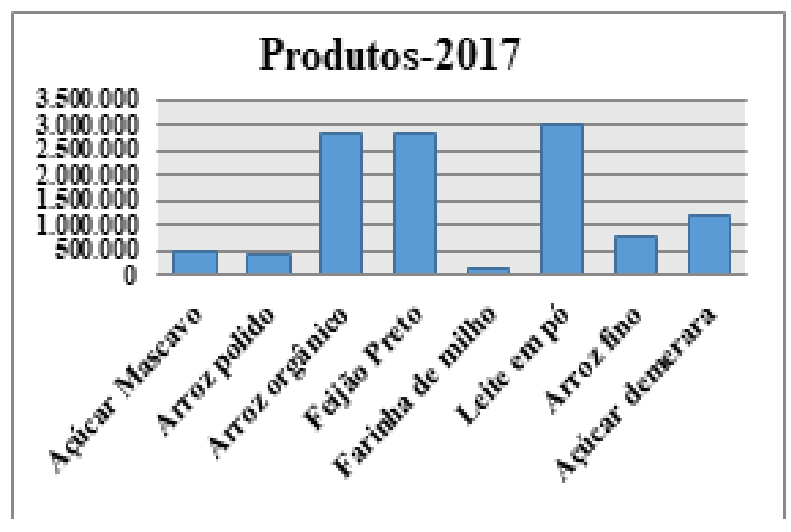

Fonte: Elaborado pelos autores. Conab. Brasil, 2019.

Figuras 10 e 11 - Chamadas na modalidade Compra Institucional do PAA no ano 2017 e 2018. Produtos e valores.

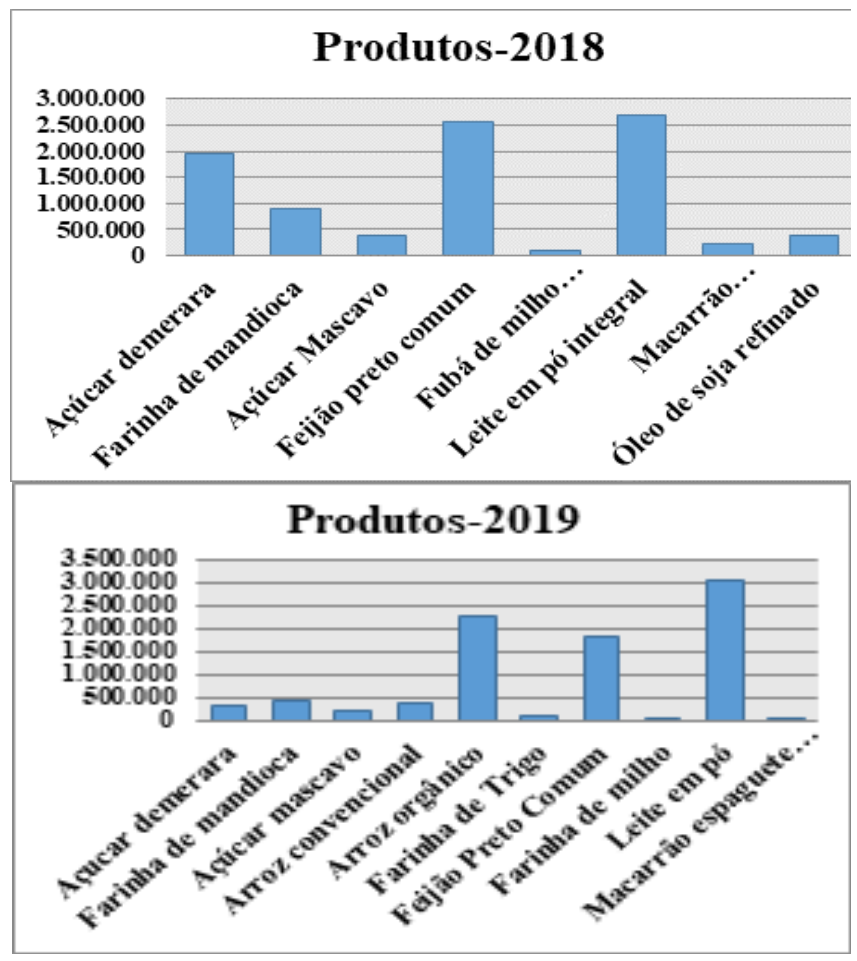

Fonte: Elaborado pelos autores. Conab. Brasil, 2019. 
Em relação aos produtos que aparecem nas Chamadas, apenas o feijão preto, um dos principais produtos presentes em todas as Chamadas, e o arroz orgânico, arroz fino e arroz polido não demandam a passagem por um processo de industrialização. Os demais variam entre um processamento que pode ser feito de forma artesanal, como no caso da farinha de mandioca e de milho e o açúcar mascavo, a produtos com alto grau de processamento como o óleo de soja refinado e o macarrão espaguete ou parafuso. Ou seja, os dados das Chamadas Públicas para o PAA Compra Institucional confirmam tratar-se de uma modalidade do programa voltada para as organizações da agricultura familiar com maior capacidade de produção e processamento de seus produtos.

Como colocado, os dados apresentados acima referem-se às compras do PAA pela modalidade Compra Institucional operacionalizadas pela Conab. Mas o Ministério da Cidadania também disponibiliza em seu site as Chamadas de instituições públicas, principalmente exército, marinha e aeronáutica, para a compra de produtos perecíveis da agricultura familiar, como hortaliças, frutas, polpas, queijo e ovos (BRASIL, 2019).

No que se refere à modalidade Compra de Sementes, de 2017 à 2019, o PAA lançou Chamadas Públicas em vários estados para a compra de sementes crioulas, variedade (não híbridas) e sem especificação da variedade. Como pode ser observado no Quadro 2, apenas em 2019 e nos estados de Minas Gerais e Mato Grosso as compras envolveram sementes de hortaliças, mais fáceis de serem produzidas por assentados, que normalmente possuem pouca terra. Ou seja, a modalidade Compra de Sementes, assim como a modalidade Compras Institucionais, tende a privilegiar os agricultores e organizações de agricultores familiares mais bem estruturados e com maior capacidade produtiva. Por outro lado, é interessante observar a quantidade de sementes crioulas e de variedades locais demandadas nas Chamadas, como feijão Rio Tibagi, Pitanga e Vereda, arroz Bonança ou milho Sol da Manhã. Essa tendência alinha-se com o objetivo de promoção de uma agricultura sustentável e enraizada em características territoriais. Considerando-se que as sementes são repassadas para órgãos como o INCRA, FUNAI, Instituto Chico Mendes e Fundação Cultural Palmares, ou seja, assentamentos, comunidades indígenas, extrativistas e quilombolas, o programa pode estar ajudando a manter sementes de variedades em processo de extinção, contribuindo assim para a preservação da herança genética dessas comunidades. 
Quadro 2 - Chamadas Públicas do PAA para a aquisição de sementes entre 2017 e 2019.

\begin{tabular}{|c|c|c|c|c|c|c|c|c|c|c|c|}
\hline ANO & UF & 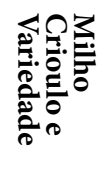 & 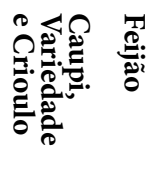 & 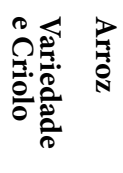 & 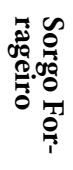 & : & 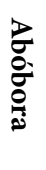 & $\frac{2}{2}$ & 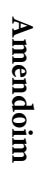 & 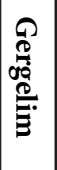 & 芯. \\
\hline \multirow{3}{*}{2017} & GO & $\mathrm{X}$ & $\mathrm{X}$ & $\mathrm{X}$ & & & & & & & \\
\hline & $\mathrm{AL}$ & $\mathrm{X}$ & $\mathrm{X}$ & & & & & & & & \\
\hline & MG & $\mathrm{X}$ & & & & & & & & & \\
\hline \multirow{7}{*}{2018} & DF & $\mathrm{X}$ & $\mathrm{X}$ & & & & & & & & \\
\hline & MG & $\mathrm{X}$ & & & & & & & & & \\
\hline & CE & $\mathrm{X}$ & $\mathrm{X}$ & & & & & & & & \\
\hline & $\mathrm{AL}$ & & $\mathrm{X}$ & $\mathrm{X}$ & $\mathrm{X}$ & & & & & & \\
\hline & RS & $\mathrm{X}$ & $\mathrm{X}$ & $\mathrm{X}$ & & & & & & & \\
\hline & SC & $\mathrm{X}$ & $\mathrm{X}$ & & & & & & & & \\
\hline & $\mathrm{AM}$ & $\mathrm{X}$ & $\mathrm{X}$ & & & & & & & & \\
\hline \multirow{6}{*}{2019} & MG & $\mathrm{X}$ & & & & $\mathrm{X}$ & $\mathrm{X}$ & & & & \\
\hline & PA & $\mathrm{X}$ & & & & & & & & & \\
\hline & PI & $\mathrm{X}$ & $\mathrm{X}$ & $\mathrm{X}$ & & & & & & & \\
\hline & $\mathrm{RS}$ & $\mathrm{X}$ & $\mathrm{X}$ & & & & & & & & \\
\hline & MT & $\mathrm{X}$ & $\mathrm{X}$ & $\mathrm{X}$ & & & $\mathrm{X}$ & $\mathrm{X}$ & $\mathrm{X}$ & $\mathrm{X}$ & $\mathrm{X}$ \\
\hline & $\mathrm{AL}$ & $\mathrm{X}$ & $\mathrm{X}$ & & & & & & & & \\
\hline
\end{tabular}

Fonte: Elaborado pelos autores, Brasil, Conab, 2019.

O crescente esvaziamento de uma política ao mesmo tempo agrícola, econômica e social atinge principalmente os produtores e grupos sociais mais alijados do desenvolvimento econômico do país. Como argumentam Valadares e Souza (2015), se por um lado as escolas continuaram a receber produtos produzidos localmente por agricultores familiares através do PNAE, entidades como asilos, albergues e demais da rede socioassistencial podem ter ficado descobertas. Igualmente preocupante é o efeito da redução do programa para a sobrevivência de associações e cooperativas da agricultura familiar.

Para Mattei (2018), a diminuição de recursos e aumento das exigências para o acesso ao programa faz parte de um pacote de ações agrárias em curso desde o início do governo Temer em 2016, que inclui a extinção do MDA, o esvaziamento do INCRA e dos serviços de assistência técnica e extensão rural nos assentamentos e a titulação de lotes, que abre margem para a sua venda no mercado de terras. 
A estratégia adotada pelo governo federal desde 2016 tem sido a de manter o PAA, evitando o desgaste político de sua completa extinção (SOUZA, 2018), mas restringir os minguados recursos a grupos específicos.

Um exemplo da recente competição entre associações e cooperativas da agricultura familiar pelos poucos recursos do PAA é o edital lançado pela Conab para a modalidade Doação Simultânea, no segundo semestre de 2019. De um total de 138 projetos submetidos no estado de São Paulo, apenas 83 podem chegar a receber recursos que somam pouco mais de sete milhões de reais. Obtiveram maior pontuação os projetos menores, de grupos formados só por mulheres ou com alta participação feminina e com características específicas como quilombolas ou afro descendentes. Por esse edital, a associação de produtores do Córrego Rico conseguiu aprovar um projeto de $\mathrm{R} \$ 80.000,00$ para um grupo formado por dez mulheres. A seguir serão apresentados dados sobre os impactos das mudanças no PAA no assentamento.

\section{ConsequênCias do esvaziamento do PAA no ASSENTAMENTo CórRego RICO}

Localizado no município de Jaboticabal/SP, o assentamento Córrego Rico é fruto das lutas por acesso à terra após as greves dos canavieiros na região no início dos anos 1980, que culminaram com o famoso "Levante de Guariba" de 1984. O assentamento era uma antigo horto florestal de 473 ha, ocupado e transformado oficialmente em assentamento pela Fundação Instituto de Terras de São Paulo (ITESP) em 1998, com 47 famílias. Atualmente, vivem no assentamento perto de 60 famílias.

No ano de 2015, quando a primeira pesquisa sobre participação em programas de políticas públicas para a agricultura familiar foi realizada no assentamento, um total de 21 famílias entregavam produtos para o PAA, na modalidade Doação Simultânea. Essas entregas eram resultado de um projeto aprovado em 2014, e esse foi o último ano em que as famílias participaram do programa através da sua "Associação de Produtores da Agricultura Familiar A Terra Rica". No total, a associação foi contemplada com três projetos do PAA a partir de 2012, sendo dois na modalidade Doação Simultânea e um complementar de Formação de Estoques.

O maior projeto contou com a participação de 39 famílias. Desde 2016 alguns produtores participam individualmente do PAA, entregando seus produtos para a prefeitura de Araraquara/SP. A pesquisa realizada em agosto de 2019 envolveu dezoito famílias, todas parte do grupo de entrevistados em 2015. Dessas, uma entregou produtos para o programa pela última vez em 2013, outra em 2015, duas em 2016, sete em 2017 e sete em 2018. Em 2019, uma produtora participou 
individualmente de uma Chamada do PNAE do município de Jaboticabal e dois produtores participaram do PPAIS. Como colocado acima, no segundo semestre de 2019 foi aprovado um novo projeto, que inclui apenas dez famílias, cujas entregas ainda não haviam iniciado no momento da elaboração deste trabalho.

Os principais benefícios do PAA para os produtores familiares, conforme atestam vários estudos, a exemplo da publicação "PAA: 10 anos de Aquisição de Alimentos" pelo antigo MDS no ano de 2014, podem ser sumarizados numa lista de itens complementares entre si: reestruturação da produção; melhoria dos preços dos produtos da agricultura familiar na região; valorização de produtos regionais e mercados locais; incentivo ao associativismo pela formação de cooperativas e associações; aumento de renda; diversificação da produção; melhoria na alimentação da família, com maior consumo de frutas e verduras; promoção da segurança e soberania alimentar; incentivo à produção orgânica e agroecológica e formação de capital social e aumento de capacidades. Essa lista de itens será utilizada para analisar os efeitos das mudanças do programa no assentamento Córrego Rico.

\section{ReEstruturaÇÃo da PRODUÇÃo}

Uma reestruturação da produção pode estar associada a vários fatores, como acesso a capital, alterações na composição da mão-de-obra familiar, ou na capacidade de empregar trabalhadores externos, introdução de novas tecnologias ou mudanças nos sistemas de criação e produção. A reestruturação está também fortemente atrelada a novas possibilidades de mercado, como os representados pelos programas de aquisição de alimentos. Grisa et al (2011) destacam a importância do PAA na promoção de maior diversificação da produção e Schmitt e Guimarães (2008) seu potencial como estimulador de processos de transição agroecológica. Nas pesquisas realizadas em 2015 e 2019 no assentamento Córrego Rico, os entrevistados apontaram como principal ponto positivo do PAA a garantia na venda da produção, como ilustrado na Figura 12.

A certeza do recebimento e o preço justo aparecem em menor proporção nas respostas dos entrevistados, talvez em decorrência dos atrasos de pagamento reportados, bem como das reclamações em relação ao preço de alguns produtos específicos. Os atrasos no pagamento e não poder entregar mais do que o teto estipulado pelo programa foram as principais dificuldades apontadas pelos entrevistados em 2015.

A garantia de venda da produção por um preço justo pode também estimular a permanência da mão-de-obra familiar na propriedade, principalmente os filhos. Mas nas duas pesquisas realizadas no assentamento, apenas em torno de $40 \%$ das famílias alegaram que a participação no PAA influenciava a decisão da família em permanecer no campo. 
Figura 12 - Principais pontos positivos do PAA, segundo os assentados do Córrego Rico.

\section{Principais pontos positivos do PAA}

\section{Fortalecimento da comunidade e união social Incentivo para produzir Comodidade, facilidade de escoamentos \\ Preço justo \\ Certezz do recebimento \\ Methoria na renda \\ Garantia de venda}

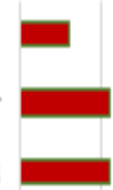

\section{$\begin{array}{lllllllll}0 \% & 10 \% & 20 \% & 30 \% & 40 \% & 50 \% & 60 \% & 70 \% & 80 \%\end{array}$}

Fonte: Pesquisa de campo, 2015 e 2019.

Quando questionados, em 2015, se a participação no PAA acarretou mudanças nas atividades produtivas, $9 \%$ dos produtores responderam que aumentaram a área plantada, 33\% que diversificaram a produção e 58\% reportaram ter tanto aumentado a área como diversificado a produção. Esses resultados são semelhantes aos encontrado por Hespanhol (2013) no município paulista de Dracena.

Na pesquisa realizada em 2019, para 12 (67\%) dos 18 produtores entrevistados, a diminuição do acesso a mercados institucionais ocasionou uma redução da área plantada ou concentração da produção em um menor número de produtos. As hortaliças foram o principal grupo de cultivos abandonado, principalmente as mais perecíveis como as folhosas. Apenas os produtores que continuaram entregando individualmente para outros mercados institucionais (PNAE e PPAIS), reportaram aumento da área plantada e diversificação da produção. Uma das produtoras aumentou a área plantada com hortaliças, mas perdeu parte da produção por falta de compradores.

A Figura 13 apresenta os resultados das respostas dos produtores quanto à distribuição dos diferentes cultivos no lote em 2015 e 2019. Foram computadas apenas as respostas dos produtores que participaram das duas pesquisas e apenas as áreas ocupadas com lavouras permanentes, anuais, hortaliças e pastagens. As áreas de preservação permanente e as ocupadas com as casas e quintais não aparecem 
no gráfico devido à dificuldade dos respondentes em precisar sua metragem.

Como pode ser observado na Figura 13, aumentou em 332\% a área ocupada com lavouras permanentes, que incluem a cana-de-açúcar e o eucalipto. Por outro lado, a área com hortaliças reportada em 2019 representa apenas 28,2\% da informada em 2015. Em relação às culturas anuais, aumentou a área plantada com milho para silagem, que é vendida em sacos de aproximadamente $30 \mathrm{~kg}$ para criadores de gado bovino do assentamento ou áreas próximas.

Em 2015, mais de 80\% dos entrevistados informaram que a renda da venda para mercados institucionais possibilitou realizar melhorias no lote, como compra ou conserto de equipamentos, reformas na casa, instalação de poços, equipamentos de irrigação, cercas, etc. Em 2019, um total de 85\% dos respondentes informaram que a participação em mercados institucionais ao longo dos anos possibilitou melhorias no lote incluindo, além dos itens já mencionados, a construção de granja para a criação de aves, compra de micro trator, freezer, embaladeira e automóvel. Ou seja, a garantia da venda e o incremento na receita incentivaram a reestruturação na produção e o investimento em melhorias no lote, como já registrado em outros trabalhos sobre o PAA (SAUZA, 2018, CRISA; PORTO, 2015).

Figura 13 - Ocupação das áreas agrícolas do lote em 2015 e 2019.

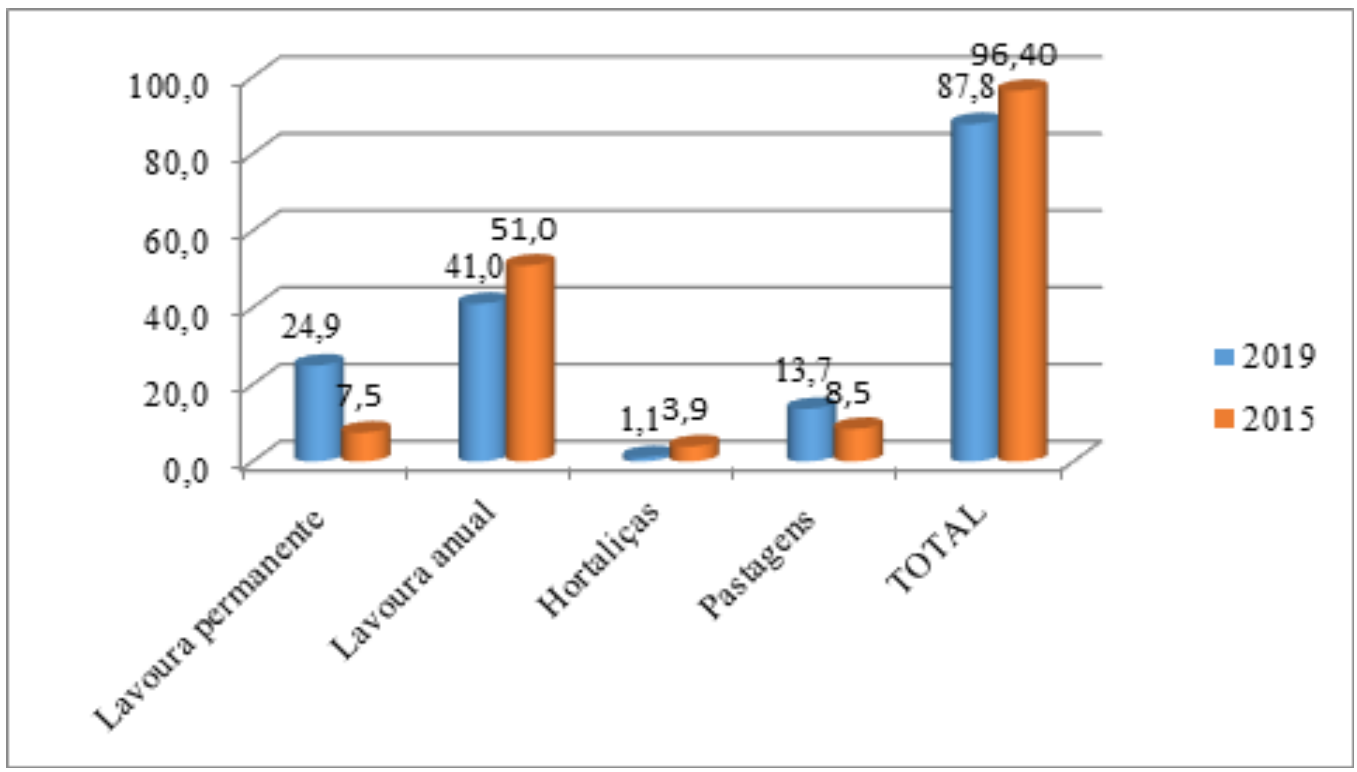

Fonte: Pesquisa de campo, 2015 e 2019. 
MELHORIA dos PREÇOS DOS PRODUTOS DA AGRICULTURA FAMILIAR NA REGIÃo

Vários estudos atestam a capacidade do PAA de melhorar os preços dos produtos da agricultura familiar na região onde opera (DELGADO, 2013; MIELITZ, 2014). Com o enxugamento dos recursos do programa, esse impacto sofreu uma importante redução, o que afeta também os preços praticados por outros mercados institucionais como o PNAE e PPAIS.

Na pesquisa realizada entre os assentados do Córrego Rico em 2015, perto de $80 \%$ dos entrevistados considerava justo os preços pagos pelo programa, mas cerca da metade indicou algum produto cujo preço ficava abaixo do praticado por comerciantes locais. Além disso, para 56\% dos entrevistados os atrasos no pagamento foram apontados como uma das grandes dificuldades do PAA. Em 2019, cerca de $87 \%$ dos entrevistados que participaram de algum mercado institucional nos últimos três anos consideraram justos os preços pagos, mas 53\% manifestou descontentamento com o preço de algum produto específico. Esse descontentamento pode ser decorrência do fato do valor pago pelo programa ser fixo, ou seja, não sofrer as variações influenciadas por sazonalidade ou condições climáticas que afetam o mercado, principalmente no caso das hortaliças.

\section{VALORIZAÇÃo de PROdUTOS REgIONAIS E MERCADOS LOCAIS}

Um dos principais benefícios do PAA para os produtores menos capitalizados, principalmente na modalidade Compra com Doação Simultânea, é o fato do programa absorver produtos que geralmente não são comercializados por questão de aceitação ou de baixo volume de produção. No assentamento Córrego Rico, a jaca produzida nos quintais de muitas casas, é um exemplo do que poderia ser chamado de mercado de ocasião, dentro de um sistema misto que combina troca mercantil com reciprocidade, típico da agricultura familiar (SABOURIN, 2014). A fruta, de comércio limitado por outras vias de mercado, ganhou valor econômico nas compras do PAA.

$\mathrm{Na}$ pesquisa de 2015, 63\% dos produtores responderam que entregavam mais de $50 \%$ de sua produção para o PAA, e $21 \%$ deles alegaram entregar de 80 a $100 \%$ de seus produtos para o programa. Em 2019 a pergunta sobre o destino atual da produção gerou a figura abaixo.

Pelo demonstrado na Figura 14, a grande maioria dos entrevistados em 2019 indicou os comerciantes atravessadores como os principais compradores de suas mercadorias. Como já mencionado, apenas três produtores entregaram para mercados institucionais nesse ano. A resposta "Outros" inclui agroindústrias processadoras de goiaba, restaurantes e vendas no próprio lote de hortaliças e silagem de milho para consumidores diretos. 
Figura 14 - Destino da produção em 2019, segundo os assentados entrevistados do Córrego Rico.

\section{Destino da produção em 2019}

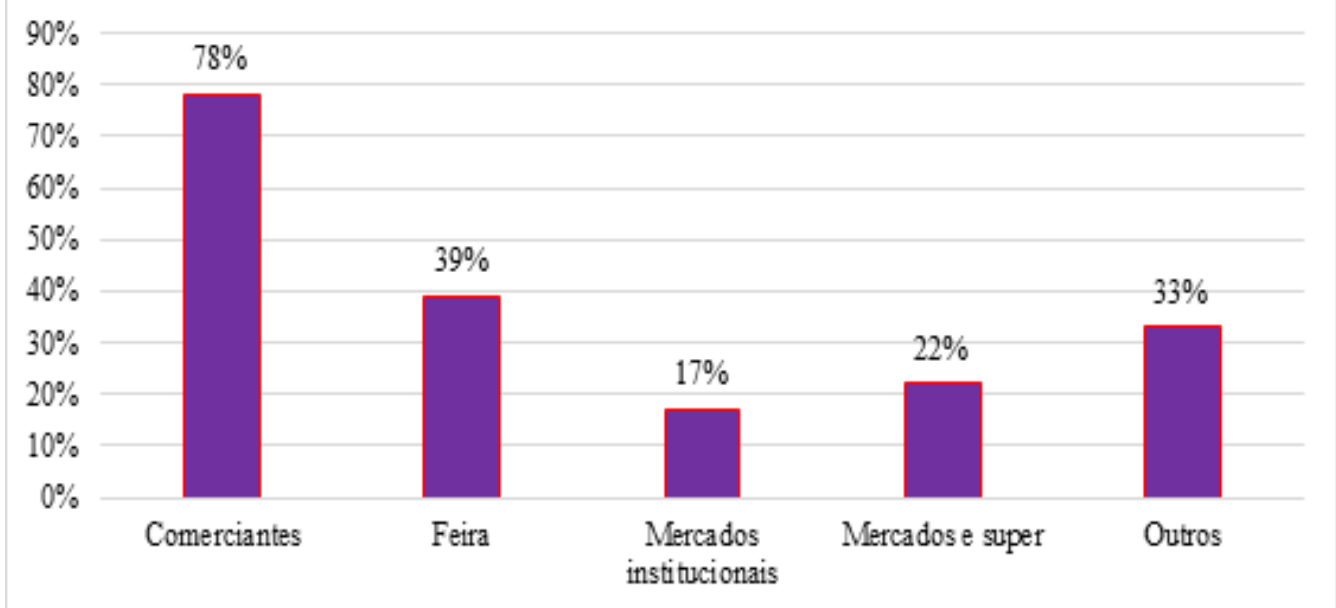

Fonte: Pesquisa de campo, 2019.

Trabalho de Porto et al (2014) atesta um aumento significativo na aquisição de produtos da biodiversidade e extrativismo pelo PAA entre 2009 e 2014, em todas as regiões do país. A revalorização de produtos regionais e tradicionais, cujo consumo ou fabricação vinham sendo abandonados (SCHIMITT; GUIMARÃES, 2008), pode ser também uma forma de garantir a transmissão geracional de costumes, conhecimentos e capacidades. No Córrego Rico, um grupo de mulheres luta para obter os certificados de inspeção sanitária necessários para comercializar compotas e doces feitos a partir de produtos locais e receitas de família. No entanto, a diminuição dos recursos do PAA afeta negativamente a lista de produtos ofertados, como será visto adiante.

InCentivo ao associativismo Pela formação de COOPERATivas e ASSOCIAÇões

A formação de organizações formais, como associações e cooperativas, para facilitar ou permitir o acesso a programas de políticas públicas é prática corrente na agricultura familiar, incentivada pelos formuladores e gestores de tais políticas e apropriada pelos produtores como forma de garantir melhor posicionamento na disputa pelos recursos do Estado (NEVES, 2013). Os problemas decorrentes 
de uma adesão não totalmente voluntária a uma forma de organização fundada na liberdade de adesão aparecem nos conflitos internos, relações personalizadas e disputas de poder entre organizações de uma mesma comunidade rural. Mas diferentes arranjos organizativos podem ser também uma estratégia de sobrevivência baseada em afinidades nem sempre evidentes ou lógicas aos olhos de interlocutores externos (OLIVEIRA; FERRANTE, 2013).

A entrega para o PAA através de uma associação ou cooperativa, no caso da operacionalização via Conab; ou individualmente, como nos casos dos termos de adesão firmados entre ministério e estados e municípios, comporta seus prós e contras. No primeiro caso, é possível listar o maior reconhecimento da organização no município, seu fortalecimento político pela capacidade de angariar projetos e também econômico, já que uma porcentagem, que pode chegar a $20 \%$ do valor dos projetos, fica para a organização. Essa é também uma forma de incluir produtores com pouca possibilidade de mobilização individual. Por outro lado, a participação individual evita o enfrentamento das disputas encontradas a miúde no interior das organizações, e que podem inibir a adesão de todos os seus membros aos projetos.

A falta de conhecimento sobre programas de políticas públicas pode ser um entrave para a sua disseminação entre o público mais carente, como produtores isolados ou que não recebem serviços de assistência técnica e extensão rural e não pertencem a organizações formais (ESQUERDO; BERGAMASCO, 2014). No caso do assentamento Córrego Rico, a associação apareceu como a principal fonte de informação sobre o PAA em 2015, quando os projetos eram enviados para a Conab pela entidade (Figura 15). Mas o protagonismo da associação diminuiu a partir de 2016, quando alguns produtores passaram a entregar individualmente seus produtos para diferentes programas de acesso a mercados institucionais (Figura 16). No segundo caso, aumentou a importância de outros mediadores, como o técnico de Ater, e outros agricultores. Ou como colocam Valadares e Souza (2015, p. 13), "se no PAA Conab as associações e cooperativas são os atores principais, no PAA Estadual e Municipal os indivíduos ocupam essa posição".

A falta de projetos para ofertar aos associados é muitas vezes apontada como a principal causa da desmotivação dos afiliados a associações e cooperativas. Programas como o PAA e PNAE impulsionaram não apenas a criação como o fortalecimento de muitas organizações da agricultura familiar (NEVES, 2013). No entanto, como alerta Xavier (2016), é preciso tomar cuidado com a dependência de recursos de programas de políticas públicas para a sobrevivência dessas organizações. 
Figura 15 - Como os entrevistados ficaram sabendo do PAA em 2015.

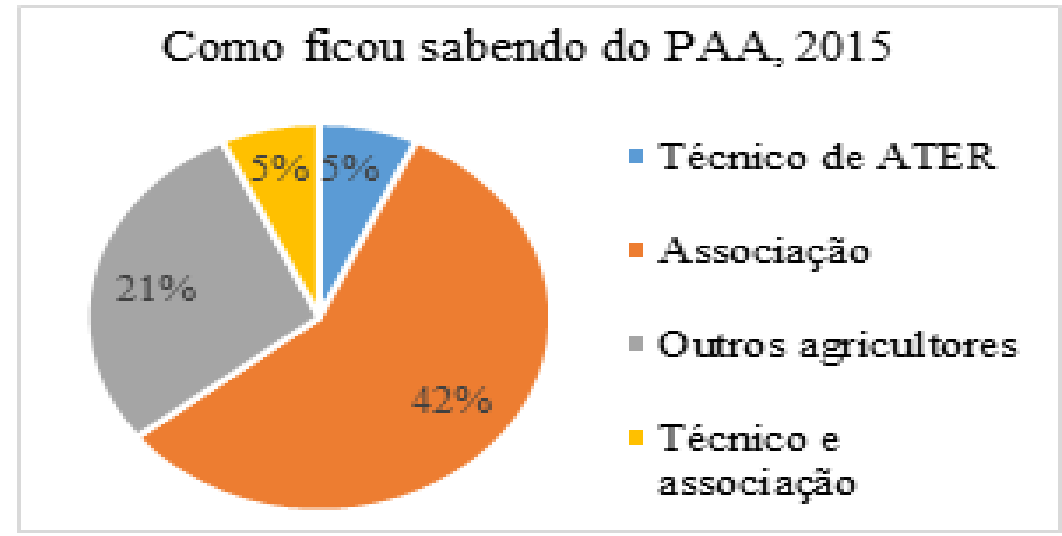

Fonte: Pesquisa de campo, 2015.

Figura 16 - Como os entrevistados ficaram sabendo de projetos de compras institucionais desde 2016.

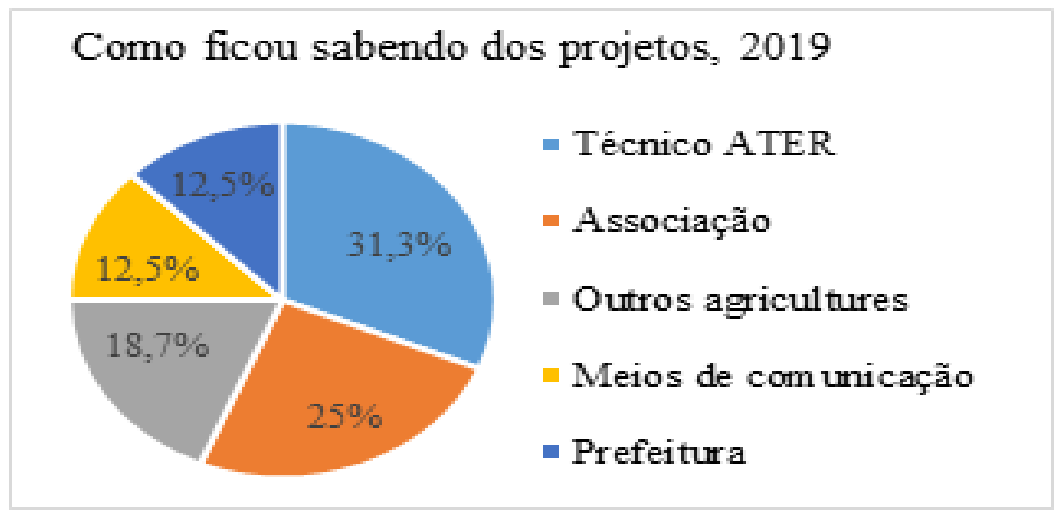

Fonte: Pesquisa de campo, 2019.

\section{Aumento de Renda}

Como na maioria das atividades econômicas, o aumento da renda na agricultura está relacionado com a diminuição dos custos de produção e aumento do volume e preço de venda dos produtos. Uma das principais vantagens do PAA, sobretudo na linha Compra com Doação Simultânea, reside justamente na possibilidade de entregar qualquer volume da produção, principalmente o excedente que os produtores tem dificuldade de comercializar por outras vias. Para Rambo et al (2016), os programas de aquisição de produtos da agricultura familiar "inovam por criarem uma demanda regular na via institucional para esse excedente de 
produção comercializável, flexibilizando as exigências de qualidade extrínsecas mencionadas, embora mantendo o atributo de frescor como um fator de qualidade a ser destacado". Os atributos que são dispensáveis não se referem à qualidade sanitária dos alimentos, mas sim a quesitos normalmente exigidos pelo mercado varejista como uniformidade, padrão, quantidade e regularidade de fornecimento.

No geral, os produtores têm dificuldade em precisar o quanto a participação em mercados institucionais aumenta a renda da família. Essa dificuldade corrobora a indivisibilidade da renda familiar nas sociedades camponesas, formada por recursos advindos de diversas fontes e complementada pelo autoconsumo (MENDRAS, 1995; WANDERLEY, 1999). Na pesquisa realizada em 2015, mais de $80 \%$ dos entrevistados informaram que a participação no PAA aumentou a renda familiar, com esse aumento chegando a 80\% em alguns casos. Em 2019, dos 14 produtores que entregaram para mercados institucionais nos últimos três anos, 12 (86\%) alegaram aumento de renda de até $50 \%$.

No questionário utilizado nas duas pesquisas, a questão sobre a renda permitia a escolha de faixas de renda. Os resultados estão agrupados na Figura 17.

Figura 17- Estimativa de renda das famílias em 2015 e 2019.

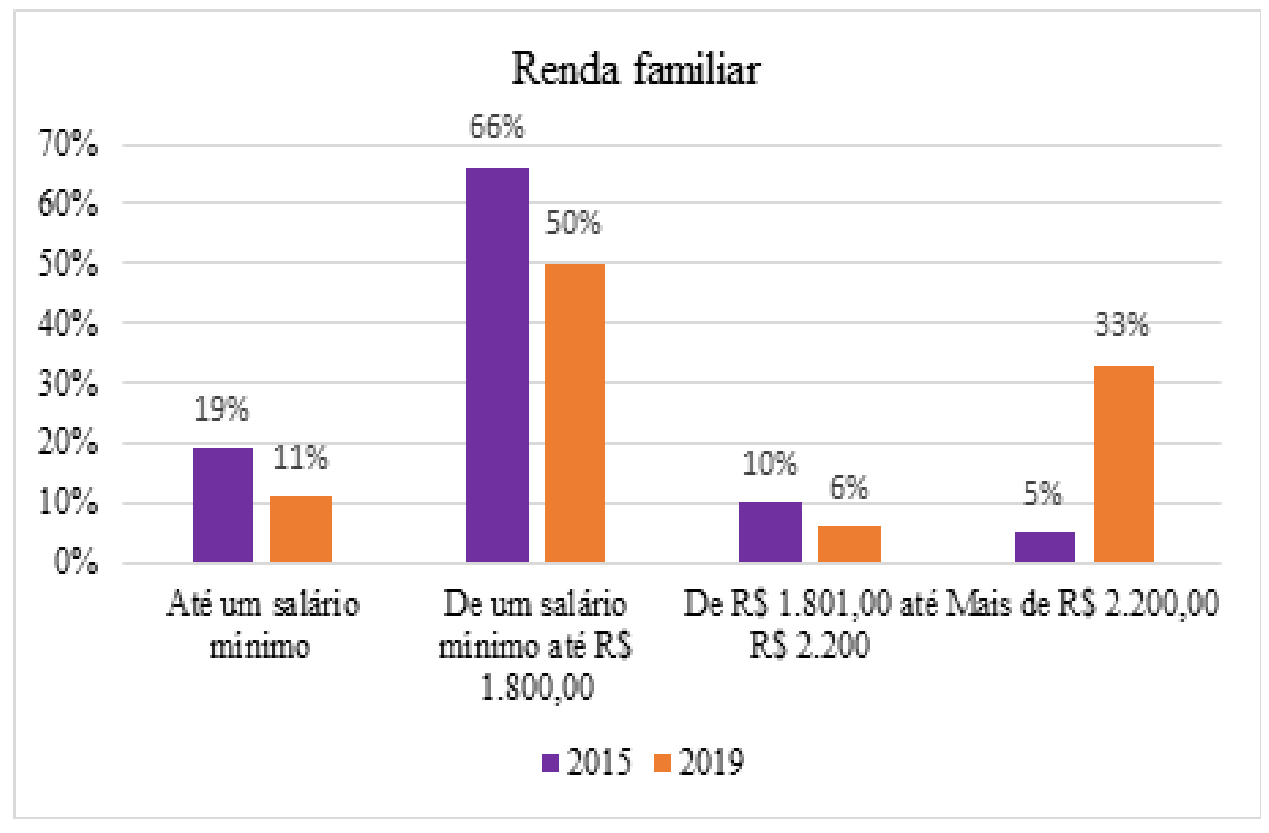

Fonte: Pesquisa de campo, 2015 e 2019. 
Como pode ser observado na Figura 17, apesar da menor participação das famílias em mercados institucionais em 2019, diminuiu o número de entrevistados que alegaram uma renda familiar nas faixas menores ${ }^{1}$ e aumentou de 5 para $33 \%$ o número de famílias com renda acima de R \$2.200,00. Uma possível explicação para a melhora na renda das famílias é o fato de que, com o aumento da idade dos responsáveis, subiu o número de famílias com pelo menos um aposentado. De fato, das dezoito famílias entrevistadas, doze (67\%) contavam com esse aporte na renda. Outro dado a ser considerado é que os valores das faixas de renda não foram atualizados, ou seja, com a inflação do período é mais fácil que uma família consiga, atualmente, uma renda superior a $\mathrm{R} \$ 2.200,00$.

\section{DiVERSIFICAÇÃo da PRODUÇÃo}

A importância do consumo para a agricultura familiar está presente nos principais estudos sobre as sociedades camponesas e modos de produção que associam trabalho, meios de produção e família (CÂNDIDO, 1987; WANDERLEY 1999; CHAYANOV, 2017). O auto consumo pode ser direto, ou seja, do próprio produto produzido, ou indireto quando, por exemplo, o milho colhido é usado para alimentar o frango que será depois consumido pela família. O consumo indireto pode estar também relacionado com a possibilidade de aquisição de maior volume ou variedade de alimentos não produzidos, em decorrência do aumento da renda pela venda da produção.

A escolha do que plantar segue, portanto, a dupla lógica do apelo mercadológico do produto e sua utilidade na alimentação da família. Essa dupla lógica faz com que muitos dos produtos cultivados pelas famílias obedeçam ao princípio da alternância (GARCIA, 1983), podendo ser direcionados para o mercado ou consumo dependendo da necessidade e das oportunidades de comercialização. Como o PAA é um programa de aquisição apenas de alimentos e sementes produzidos pela agricultura familiar, é possível afirmar que todos os produtos plantados e entregues para o programa seguem o princípio da alternância.

Os projetos de compra operacionalizados pela Conab em 2012, ano de maior volume de recursos do PAA, contemplaram 604 produtos diferentes (VALADARES; SOUZA, 2015), demonstrando a grande diversidade produtiva encontrada na agricultura familiar e a possibilidade de inclusão de produtos regionais ou de pouco valor comercial no programa. No caso do assentamento Córrego Rico, a pesquisa realizada em 2015 encontrou um total de 26 produtos entregues pelas famílias assentadas ao PAA. Desses, dezesseis são classificados como hortaliças, sete como frutas, dois como grãos e um como tubérculo.

\footnotetext{
${ }^{1}$ Salário mínimo de R\$998,00.
} 
A mandioca foi o produto mais entregue para o mercado institucional, presente em $85 \%$ das entrevistas. Pelas respostas da pesquisa atual foi possível apurar que em 2017 foram entregues treze tipos de produtos para mercados institucionais, em 2018 dez tipos de produtos e em 2019 apenas sete. A diminuição na variedade de produtos coincide com a redução dos recursos do PAA e com a maior dificuldade de acesso, já que nos últimos três anos predominaram as participações individuais.

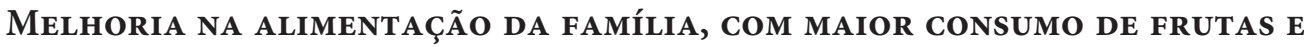
HORTALIÇAS

Como colocado acima, os produtos entregues para o PAA seguem o princípio da alternância, podendo ser comercializados ou consumidos pela família. Quando perguntados, em 2015, se a participação no PAA modificou a alimentação da família, 50\% dos entrevistados respondeu que sim. Os produtos que essas famílias passaram a consumir em maior quantidade aparecem na Figura 18. Como seria de se esperar, as hortaliças lideraram a lista.

Figura 18 - Produtos que as famílias passaram a consumir em maior quantidade após participação no PAA.

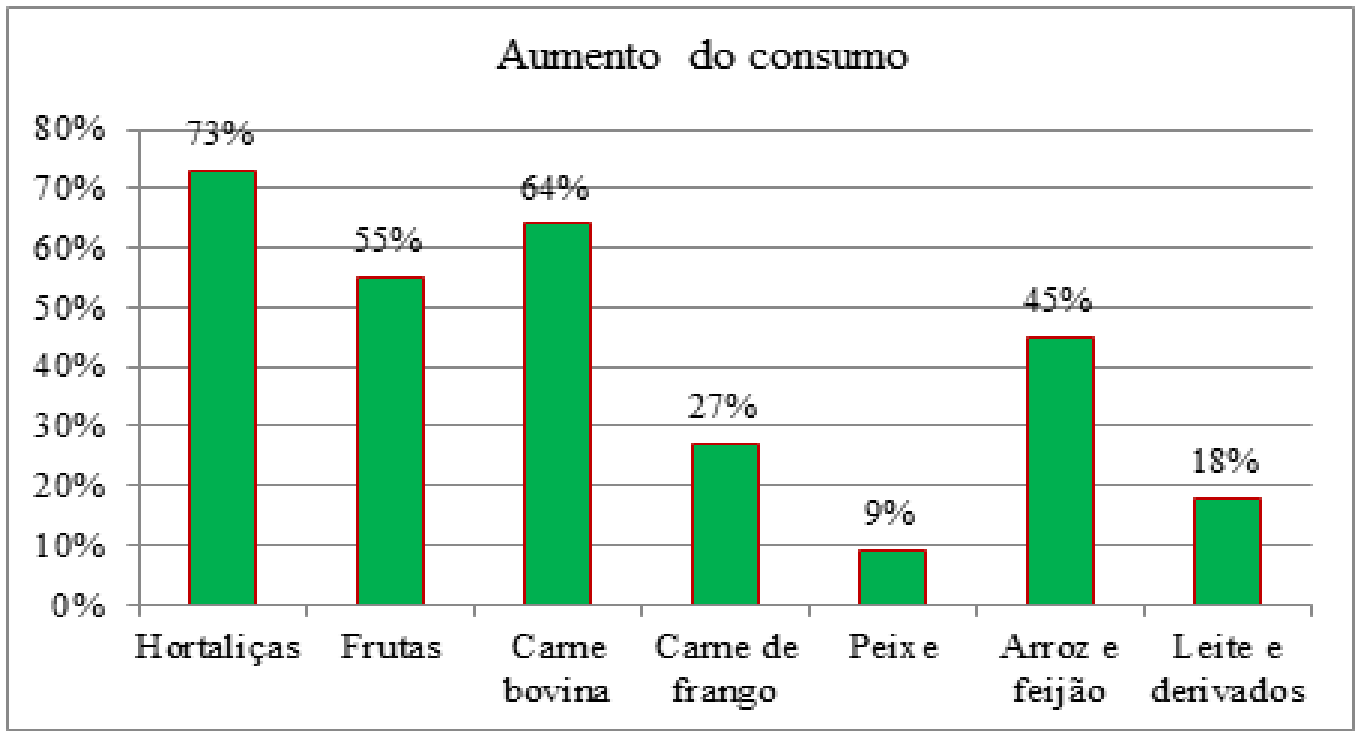

Fonte: Pesquisa de campo, 2015

Na pesquisa realizada em 2019, os entrevistados voltaram a indicar os mesmos itens como produtos alimentícios que passaram a consumir em maior quantidade quando produziam e entregavam para o PAA. Por outro lado, apontaram as 
hortaliças como o grupo de alimentos que mais diminuíram o consumo na ausência do programa. Além da produção geralmente estimular o consumo de qualquer grupo de alimentos, no caso das hortaliças a grande perecividade da maioria dos vegetais impede o armazenamento prolongado, incentivando o seu uso pela família ou emprego na alimentação animal. Essa necessidade de consumo rápido "prá não perder", estimula a "invenção" de novos pratos ou formas de consumir o mesmo vegetal. O excedente da produção de hortaliças é também muitas vezes doado para vizinhos e parentes, fortalecendo os laços de solidariedade e reciprocidade dentro e fora da comunidade rural.

Justamente por sua alta perecividade, as hortaliças são os produtos que mais sofrem substituições nas vendas para mercados institucionais. Nesse sentido, é necessário que programas federais como o PAA e PNAE, ou estaduais como o PPAIS, adotem uma postura de flexibilidade em relação a substituição do produto originalmente listado no projeto e não considerem como ilegal a troca de produtos entre os produtores participantes do mesmo projeto de venda.

$\mathrm{O}$ aumento no consumo de frutas e hortaliças, muitas vezes produzidos sem o uso de agrotóxicos, tem um impacto direto na saúde e segurança alimentar e nutricional dos produtores familiares, como retratado nos estudos sobre o PAA analisados por Assis et al (2017).

\section{Promoção da Segurança e Soberania Alimentar}

No Brasil, a segurança alimentar da população é aferida de várias maneiras, dentre elas através da medição do seu oposto, ou seja, do número de famílias que vivem em situação de insegurança alimentar. Para tanto, é utilizada a Escala Brasileira de Medida de Insegurança Alimentar (EBIA), metodologia adaptada para a realidade brasileira da norte americana Household Food Security Survey Module, uma escala psicométrica para a medida direta da segurança ou insegurança alimentar da família (SEGALL-CORRÊA; MARIN-LEON, 2009). Pela EBIA, a insegurança alimentar pode ser classificada em leve, moderada ou grave, dependendo do número de respostas afirmativas de um questionário com quatorze perguntas. O questionário da EBIA foi aplicado nos assentados do Córrego Rico que participavam do PAA em 2015 e 2019.

Pelos resultados apresentados na Figura 19, no intervalo entre as duas pesquisas aumentou o número de famílias com segurança alimentar e diminuiu as com insegurança leve; mas aumentaram também os casos de insegurança moderada. O aumento do número de famílias com segurança alimentar pode estar associado com o aumento da renda, já discutido acima. Na pesquisa de 2015 as famílias com insegurança alimentar moderada declararam renda familiar de menos de um 
Figura 19 - Presença de insegurança alimentar entre as famílias entrevistadas.

Resultado EBIA 2015

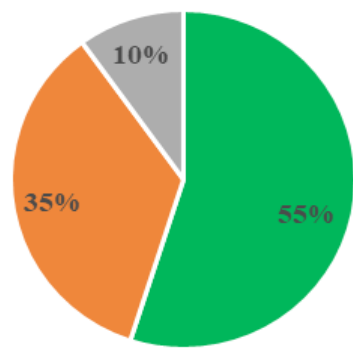

Resultado EBIA 2019
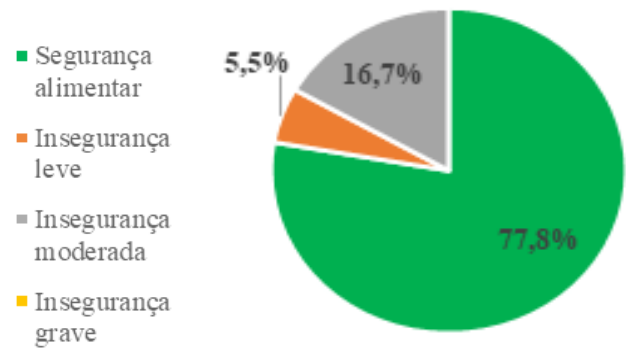

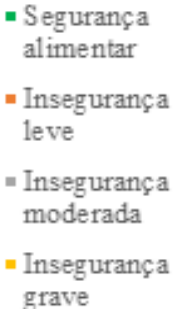

grave

Fonte: Pesquisa de campo, 2015 e 2019.

salário a um salário mínimo por mês. Na pesquisa atual, as três famílias com insegurança alimentar moderada encontravam-se em três faixas de renda: menos de um salário mínimo, de um salário mínimo até R\$1.200,00/mês (nesse caso a principal fonte de renda era a aposentadoria do marido) e de R \$1.201,00 até R\$ $1.800,00 /$ mês, caso de família pluriativa com dois filhos que exerciam trabalho não agrícola fora do assentamento. Apesar de importante para a segurança alimentar, um aumento na renda familiar não acarreta, necessariamente, melhoria na alimentação da família, como comprovam alguns estudos do efeito de programas de transferência de renda no consumo alimentar (ALMEIDA, et al, 2017).

Das famílias que apresentaram algum nível de insegurança alimentar em 2019, duas não entregavam produtos para o PAA desde 2015, uma participou do programa pela última vez em 2017 e a outra em 2018. Também é interessante observar que três das quatro famílias com insegurança alimentar em 2019 repetiram o resultado da pesquisa de 2015. A EBIA questiona não apenas se a família teve o que comer durante o dia, mas se a dieta foi considerada saudável e variada pelo respondente. Apesar de subjetiva, a questão relaciona-se com o acesso aos cinco grupos de alimentos considerados importantes para uma dieta completa. Nesse caso, a diversificação da produção e do autoconsumo propiciada pelo PAA tem papel importante na qualidade da dieta familiar (ASSIS, et al, 2017). Assentamentos rurais, mesmo quando próximos da cidade como no caso do Córrego Rico, geralmente apresentam dificuldades de transporte que impedem a ida frequente a centros de comércio, o que dificulta a aquisição de produtos perecíveis como hortaliças e frutas.

\section{INCENTIVO À PRODUÇÃo ORGÂNICA E AGROECOLÓGICA}

Para Schimitt e Guimarães (2008, p.8), a compra de produtos agroecológicos 
da agricultura familiar por mercados institucionais, “[...] introduzem novos elementos no debate sobre o lugar dos mercados na transição para uma agricultura de base ecológica. Provocam também uma reflexão acerca do papel do Estado na reestruturação dos circuitos de produção, distribuição e consumo de alimentos com base em princípios de justiça social e sustentabilidade ambiental”.

As normas do PAA preveem o pagamento de até 30\% a mais para produtos orgânicos e agroecológicos, mas no caso dos assentados pesquisados no Córrego Rico, nenhum produtor recebeu esse acréscimo, embora em 2015 perto de $30 \%$ dos entrevistados se considerassem produtores orgânicos por não fazer uso de defensivos químicos. Na pesquisa de 2019, entre os oito produtores que entregaram produtos para mercados institucionais em 2018 e 2019, três alegaram que já produzem sem o uso de agroquímicos, mas não são certificados nem recebem a mais pelos produtos. Quatro responderam não ter ainda produção orgânica, mas demonstraram interesse em produzir dessa forma, principalmente pelo incremento no preço do produto, e dois afirmaram não ter interesse na produção orgânica.

A compra de produtos orgânicos ou agroecológicos com preço diferenciado pode mostrar-se lenta também em áreas de assentamento formadas como Projetos de Desenvolvimento Sustentável no estado de São Paulo (CAMARGO et al, 2016). Estudo de Galindo et al (2014) com os dados da Conab e MDS revelou que o volume de compras de orgânicos pelo PAA aumentou, passando de R\$ 6,6 milhões em 2007 para $\mathrm{R} \$ 13,2$ milhões em 2012, com a região Sul liderando as compras. No entanto, vários estados não apresentaram compra alguma ou apenas em alguns anos durante o período estudado e a participação de produtos orgânicos e agroecológico não passou de 3\% do valor total operacionalizado pelo programa. Os autores apontam a dificuldade em obter a certificação como o principal impedimento para a venda de orgânicos com preços diferenciados para o PAA, principalmente para produtores da biodiversidade e do extrativismo. Como colocado acima, a pesquisa no Córrego Rico também indicou a venda de produtos produzidos sem o uso de agroquímicos para mercados institucionais como convencionais, por falta de certificação.

A legislação brasileira permite a certificação por pares, que diminui seu custo em relação a certificação por auditoria, e também a formação de Organizações de Controle Social (OCSs) para a venda direta e para mercados institucionais de produtos orgânicos e agroecológicos sem o selo "Produto Orgânico Brasil" emitido pelo MAPA. Mas as medidas para facilitar a certificação não sanam a falta de profissionais habilitados para oferecer um serviço de assistência técnica e extensão rural com foco em processos de transição agroecológica. Em 2015, a falta de assistência técnica foi apontada como uma grande dificuldade para a entrega de 
produtos para o PAA, por 38\% dos entrevistados. Em 2019, metade dos assentados pesquisados apontou a falta de assistência técnica como uma dificuldade entre moderada e grande para a produção e participação em mercados institucionais.

\section{FORMAÇÃo DE CAPITAL SOCIAL E AUMENTO DE CAPACIDADES}

A formação de um capital social, base para o acesso às esferas de mercado, administração pública e da sociedade civil frequentemente alijadas do universo da agricultura familiar, é defendida por Grisa (2009) como um dos efeitos do PAA, quando estudado a luz das teorias de Antony Bebbinton. A autora aponta também a interface do programa com o capital natural e cultural. No caso do capital natural, pelo estímulo à uma produção diversificada e seu potencial de impulsionar processos de transição agroecológica. Mas pode também fortalecer o capital cultural inerente ao campesinato e fundado no policultivo, na produção para o autoconsumo e valorização de produtos regionais, ou ainda estimular as relações de troca e solidariedade defendidas por Sabourin (2014). A formação de redes locais de produção e consumo também é destacada por Schimitt e Guimarães (2008) como um dos resultados positivos esperados do PAA, bem como a aquisição de maior habilidade para organizar a produção, interagir com representantes da administração governamental e com as regras do mercado (SCHIMITT, et al, 2014). O trabalho de Oliveira e Ferrante (2013), ao estudar outra área de assentamento, localizada na região de Ribeirão Preto do estado de São Paulo, identifica a participação no PAA como meio de ampliar as capacidades individuais e coletivas e promover o desenvolvimento da comunidade. Entre essas capacidades encontra-se uma maior habilidade para lidar com os mercados, sejam institucionais ou de outra natureza.

Para Sabourin (2014, p. 29):

Os mercados públicos com preços garantidos constituem um instrumento de política pública de articulação ou de interface entre sistemas de troca mercantil e sistemas de reciprocidade. De fato, tais políticas introduzem uma dimensão de reciprocidade e de justiça num sistema dominado pela troca capitalista como aquele dos mercados agropecuários no Brasil.

Com a diminuição dos recursos do PAA, e até mesmo sua possível extinção em governos futuros, é importante indagar que legado a participação em mercados institucionais via esse programa deixou para as comunidades e organizações de produtores familiares no sentido de participação em redes de valorização de seus produtos. No caso do assentamento Córrego Rico, a participação individual de alguns produtores na rede de fornecedores da prefeitura de Araraquara pode 
ser considerado um exemplo de inserção em um mercado social construído (ALMEIDA; FERRANTE, 2009). Mas, por outro lado, o fato de nenhum produtor ter entregue para aquele município em 2019 demonstra a fragilidade e dependência das oscilações políticas desse mercado.

Apesar dos problemas enfrentados atualmente pelo PAA, éimportante ressaltaro aprendizado decorrente do acesso a mercados institucionais e das negociações com várias esferas da administração pública, que ampliou o capital social e as capacidades das organizações da agricultura familiar. No caso recente da participação de um grupo de mulheres do Córrego Rico no edital da Conab de 2019 para o PAA Doação Simultânea, a aprovação do projeto só foi possível pela rede de conhecimentos da presidente da associação de produtores do assentamento, que faz parte também do Conselho Municipal de Segurança Alimentar e Nutricional (CONSEAN).

As relações pessoais são um atributo importante na construção de mercados para os agricultores familiares que, na sua grande maioria, participam de mercados imperfeitos e parciais, uma vez que limitados pelo pequeno volume de produção, dificuldades de transporte e falta de informações - que dificultam a participação em "mercados perfeitos" regidos pela livre concorrência. Ainda que muito próximos da sede do município, os assentados do Córrego Rico enfrentam problemas como a falta de veículo próprio ou carteira de motorista e a má conservação das estradas, que impedem sua maior inserção em formas diretas de comercialização, como as feiras livres e a venda de porta em porta, aumentando a dependência dos comerciantes atravessadores.

A participação conjunta em mercados institucionais, através de organizações formais e informais, desencadeia processos de "aprendizagem partilhada" (RAMBO et al, 2016 p. 123), que fortalecem os laços sociais entre os produtores e aumentam sua capacidade de negociação com outros agentes do mercado local. Mas é também importante lembrar que essa mesma interação pode criar conflitos internos que afetam relações de solidariedade naturais ou, no caso dos assentamentos rurais, construídas ao longo da luta pelo acesso à terra.

\section{CONSIDERAÇõES FINAIS}

A valorização da produção familiar passa pelo acesso a diferentes tipos de mercados, sejam eles institucionais, de venda direta aos consumidores ou mesmo de exportação. Quanto mais local for o mercado e mais próximo o consumidor final, mais a troca mercantil é permeada por relações de reciprocidade. Mas a inserção dos produtores menos estruturados e capitalizados em qualquer forma de mercado demanda o reconhecimento e valorização econômica do leque de possibilidades que o conceito de agricultura familiar abarca. 
O Programa de Aquisição de Alimentos inovou em diversas frentes, ao propor a inserção dos produtos da agricultura familiar em mercados institucionais mediante a participação em suas diferentes modalidades. Sobretudo a linha Compra com Doação Simultânea possibilitou a valorização econômica de produtos até então marginais na produção mercantil familiar, bem como os resultantes do extrativismo e da biodiversidade. A interface com a segurança alimentar e o desenvolvimento rural e a valorização dos produtos regionais, agroecológicos e orgânicos e dos circuitos curtos de comercialização alinhavam o programa com os objetivos de desenvolvimento sustentável defendidos pela ONU.

Mas, atualmente, o PAA, que já foi uma referência de política pública no Brasil e em diversos países, encontra-se com um volume de recursos e de público demasiado reduzidos para que se cumpra seu dublo objetivo de fortalecimento da agricultura familiar e promoção da segurança alimentar. A modalidade mais acessada passou a ser a Compra Institucional, que não depende de liberação de recursos para o programa. Ainda que a modalidade, operacionalizada por Chamadas Públicas, represente um mercado interessante para produtores familiares e suas organizações, tende a privilegiar os mais bem estruturados e já inseridos em outras formas de mercado. No outro extremo, encontram-se os parcos recursos, liberados a conta gotas, para projetos de doação simultânea, atualmente voltados para grupos pequenos e específicos. Mesmo que se argumente que esses grupos representam as camadas mais marginalizadas da agricultura familiar, o número de produtores atendidos fica ainda mais aquém das necessidades e contingente de produtores familiares, diminuindo drasticamente o potencial do programa de impulsionar processos de desenvolvimento rural locais.

No intervalo de quatro anos entre as duas entrevistas realizadas no assentamento Córrego Rico (2015 e 2019), o principal efeito encontrado do esvaziamento do PAA foi a crescente desmotivação para a diversificação da produção - a área com o cultivo de hortaliças foi reduzida consideravelmente e aumentada a porção do lote ocupada com culturas perenes. A perda da produção por falta de comparadores, reportada por alguns dos entrevistados, reverbera o questionamento que dá título a esse trabalho: "plantar prá que?". Ainda que não tenha sido possível detectar uma diminuição da segurança alimentar e da renda familiar em decorrência do esvaziamento do PAA, houve uma redução na variedade de espécies produzidas e na presença de frutas e hortaliças na dieta das famílias.

Por outro lado, na fase final da elaboração desse trabalho, foi aprovado o projeto do grupo de dez mulheres, para um edital do PAA de 2019. Essa aprovação renovou as expectativas do grupo em produzir e comercializar a produção, e foi possível observar os primeiros indícios da retomada de antigos cultivos de 
hortaliças nos lotes contemplados. Essa resposta reforça a importância do acesso à mercados institucionais para a reprodução da agricultura familiar enquanto forma de produção que cumpre diversas funções no meio rural.

A pesquisa de campo também comprovou o legado de aprendizado deixado pela participação nas fases anteriores do PAA, e que pode auxiliar agricultores familiares individuais ou organizados em cooperativas e associações a lograr inserção nos programas de mercados institucionais encontrados no estado de São Paulo - PAA, PNAE e PPAIS.

\section{REFERÊNCIAS}

ALMEIDA, J. A. et al. Fatores associados ao risco de insegurança alimentar e nutricional em famílias de assentamentos rurais. Revista Ciência e Saúde Coletiva, 22(2), p. 479-488, 2017.

ALMEIDA, L. M. M. C.; FERRANTE, V. L. B. Programa de segurança Alimentar e Agricultores Familiares: A formação de rede de forte coesão social a partir do programa de aquisição de alimentos (PAA) no município de Araraquara-SP. In Anais, 47 Congresso da SOBER, Porto Alegre, 2009.

AQUINO, J. R.; SCHNEIDER, S. O Pronaf e o desenvolvimento rural brasileiro: avanços, contradições e desafios para o futuro. In: GRISA, C.; SCHNEIDER, S. Políticas públicas de desenvolvimento rural no Brasil. Porto Alegre: Editora da UFRGS, 2015.

ASSIS, S. C. R.; PRIORI, S. E.; FRANCESCHINI, S., C. C. Impacto do Programa de aquisição de Alimentos na Segurança Alimentar e Nutricional dos Agricultores. Revista Ciência e Saúde Coletiva, 22(2), p. 617-626, 2017.

BRASIL. Ministério da Cidadania. Inclusão produtiva rural. Disponível em: http:// www.desenvolvimentosocial.gov.br/servicos/inclusao-produtiva-rural. Acesso em 03.12.2019

CANDIDO, Antônio. Os Parceiros do Rio Bonito. São Paulo: Livraria Duas Cidades, $7^{\text {a }}$ Edição, 1987.

CAMARGO, R. A. L.; BACCARIN, J.G.; SILVA, D. B. P. Mercados institucionais para a agricultura familiar e soberania alimentar. Revista NERA (UNESP), v.32, p.34 - 55, 2016. 
CAMARGO, R.A.L; BACCARIN, J.G; SILVA, D.B.P. O papel do Programa de Aquisição de Alimentos (PAA) e do Programa Nacional de Alimentação Escolar (PNAE) no fortalecimento da agricultura familiar e promoção da segurança alimentar. Revista Temas de Administração Pública. Araraquara-SP: FCLAr/UNESP, v. 8, n. 2, 2013.

CAMARGO, R. A. L.et al. O PAA e PNAE em assentamentos PDS no norte paulista. Revista Retratos de Assentamentos, v. 19, n. 1, p. 149-173, 2016.

CASTRO, C. M. Contribuições do PAA África para o processo de consolidação do PRONAE em Moçambique. FAO. Working Paper 170, junho de 2018.

CHAYANOV, A. Teoria das Cooperativas Camponesas. Porto Alegre: Editora UFRGS, 2017.

CONAB. Agricultura Familiar Programa de Aquisição de Alimentos - PAA: Resultados das Ações da Conab em 2018. Compêndio de Estudos da Conab, v. 20. Brasília, 2019.

CONAB. Transparência Pública do PAA. Disponível em: https://consultaweb. conab.gov.br/consultas/consultatransparenciapaa.do?method=abrirConsulta. Acesso em 28/11/2019.

DELGADO, G. C. Pesquisa de avaliação de concepção e implementação do Programa Aquisição de Alimentos - PAA: relatório de avaliação do PAA (Síntese). Brasília: Conab; PNUD, 2013.

DELGADO, G. C. BERGAMASCO, S. M. P. P. (orgs.). Agricultura familiar brasileira: desafios e perspectivas de futuro. Brasília: Ministério do Desenvolvimento Agrário, 2017.

FARAH, M.F.S. Inovação e governo local no Brasil contemporâneo. In: JACOBI, P. Pinho, J. A (org). Inovação no campo da gestão pública local: novos desafios, novos patamares. Rio de Janeiro: Editora FGV, 2006.

FARAH, M.F.S. Disseminação de inovações e políticas públicas e espaço local. Organizações e Sociedade. v 15, n.45, p.107-126, 2008.

GARCIA JR. Afrânio Raul. Terra de Trabalho. Trabalho Familiar de Pequenos 
Produtores. Rio de Janeiro: Paz e Terra, 1983.

GALINDO, E.P; SAMBUICHI, R. H. R; OLIVEIRA, M. A. C; Compras de produtos agroecológicos e orgânicos pelo Programa de Aquisição de Alimentos. In: PAA: 10 anos de aquisição de alimentos. Brasília: MDS, 2014.

GRISA, C. Desenvolvimento local, políticas públicas e meios de vida: uma análise do programa de Aquisição de Alimentos (PAA). In Anais, 47 Congresso da SOBER, Porto Alegre, 2009.

GRISA, C.; SCHMITT, C. J.; MATTEI, L. F.; MALUF, R. S.; LEITE, S. P. Contribuições do Programa de Aquisição de Alimentos à segurança alimentar e nutricional e à criação de mercados para a agricultura familiar. Agriculturas, v. 8, n. 3, p. 34-41, 2011.

GRISA, C.; PORTO, S.I. Dez anos de PAA: as contribuições e os desafios para o desenvolvimento rural. In: GRISA, C.; SCHNEIDER, S. Políticas públicas de desenvolvimento rural no Brasil. Porto Alegre: Editora da UFRGS, 2015.

HESPANHOL R. A. M. Programa de Aquisição de Alimentos: limites e potencialidades de políticas de Segurança Alimentar para a agricultura familiar. Revista Sociedade e Natureza, v.25, p.469-483, 2013.

MALUF, R. S. et al. Nutrition-sensitive agriculture and the promotion of food and nutrition sovereignty and security in Brazil. Revista Ciência e Saúde Coletiva, v.20, p. 2303-2312, 2015.

MATTEI, L. A Política Agrária e os Retrocessos do Governo Temer. Revista OKARA: Geografia em debate, v.12, p. 293-307, 2018.

MATTEI, L. Políticas públicas de apoio à agricultura familiar: o caso recente do Pronaf no Brasil. Revista Raízes. Campina Grande, v.35, n.1, jan-jun /2015.

MENDRAS, Henri. Les sociétés paysannes. Paris: Éditions Gallimard, 1995.

MIELITZ, C. Dez anos de PAA e a constituição de uma estratégia nacional de segurança alimentar. In: PAA: 10 anos de aquisição de alimentos. Brasília: MDS, 
2014.

NEVES, D. P. Associativismo e personalismo dos mediadores formais: dilemas da organização política de assentados rurais pela Intervenção estatal. Revista Retratos de Assentamentos, v.16, n.1, p. 15-42, 2013.

OLIVEIRA, P.M.; FERRANTE, V.L.S.B. O Programa de Aquisição de Alimentos no PDS Sepé Tiarajú: bloqueios e perspectivas. Retratos de Assentamentos, v.16, n.1, 2013.

PLOEG, J.D.V.D. Camponeses e impérios alimentares: luta por autonomia e sustentabilidade na era da globalização. Porto Alegre (RS): Editora da UFRGS, 2008.

PORTO, S.I. et al. Programa de Aquisição de Alimentos (PAA): dez anos de uma política pública múltipla e inovadora. In: BRASIL, MDS. PAA: 10 anos de aquisição de alimentos. Brasília: MDS, 2014.

RAMBO, J. R.; COSTA, S.M.A.L; LAFORGA, G. Aspectos inovativos presentes nas atuais políticas públicas de aquisição de alimentos da agricultura familiar brasileira. Revista Raízes, Campina Grande, v.36, n. 2, jul-dez/2016.

SABOURIN E. Acesso aos mercados para a agricultura familiar: uma leitura pela Reciprocidade e a economia solidaria. Revista Econômica do Nordeste, Fortaleza, v. 45, suplemento especial, p. 21-35, out./dez., 2014.

SABOURIN E.; GRISA C. (Orgs). A difusão de políticas brasileiras para a agricultura familiar na América Latina e Caribe. Porto Alegre: Escritos Editora, 2018.

SALES, J. O. A criminalização da agricultura camponesa: o caso da operação Agro-Fantasma no Brasil. In: Anais, XXXI Congreso ALAS. Montevideo, 2017.

SCHIMITT, C. J.; GUIMARÃES, L. A. O mercado institucional como instrumento para o fortalecimento da agricultura familiar de base ecológica. Agriculturas, v. 5, n. 2, p. 7-13. 2008.

SCHIMITT, C. J. et al. O Programa de Aquisição de Alimentos em assentamentos de reforma agrária: implantação, impactos e perspectivas. In: BRASIL, MDS. 
PAA: 10 anos de aquisição de alimentos. Brasília, DF: MDS, p. 152-183, 2014.

SEGALL-CORRÊA, A. M.; MARIN-LEON, L. (1). A segurança alimentar no Brasil: proposição e usos da escala brasileira de medida da insegurança alimentar (EBIA) de 2003 a 2009. Segurança Alimentar E Nutricional, 16(2), 1-19, 2009.

SOARES, R. P. O Financiamento do Banco Mundial ao Programa de Apoio ao Pequeno Produtor Rural do Nordeste (PAPP). Texto para Discussão 435. Brasília, IPEA, 1996.

SOUZA-ESQUERDO, V, F; BERGAMASCO, S, M. P. P. Análise sobre o acesso aos programas de políticas públicas da agricultura familiar nos municípios do circuito das frutas (SP). Rev. Econ. Sociol. Rural [online]. vol.52, suppl.1, p.205-222, 2014.

SOUZA, J. R. M. a Política de Aquisição de Alimentos na mira do golpe. Revista OKARA: Geografia em debate, v.12 n, 2, p. 664-677, 2018.

SPINK, P. A inovação na perspectiva dos inovadores. In: JACOBI, P. Pinho, J. A (org). Inovação no campo da gestão pública local: novos desafios, novos patamares. Rio de Janeiro: Editora FGV, 2006.

TRICHES, R. M.; GRISA, C. Entre mudanças e conservadorismos: uma análise dos programas de aquisição de alimentos (PAA e PNAE) a partir da retórica da intransigência. Revista NERA. Presidente Prudente, ano 18, nº 26, p. 10-27, 2015.

VALADARES, A. A; SOUZA, M. G. P. A trajetória recente do Programa de Aquisição de Alimentos da Agricultura Familiar (PAA): Uma análise das mudanças normativas e institucionais que deram nova inflexão ao programa. Nota Técnica no 21. Brasília: IPEA, 2015.

XAVIER, M.L.B. O Programa de Aquisição de Alimentos nas Cooperativas Catarinenses. Florianópolis: Editora Insular, 2016.

WANDERLEY, Maria Nazareth B. Raízes históricas do campesinato brasileiro. In TADESCO, João Carlos (Org.). Agricultura familiar: realidades e perspectivas Passo Fundo: EDIUPF, 1999. 